\title{
ARTRÓPODOS PRESENTE EM CAMINHÕES QUE TRANSPORTAM MATÉRIAS-PRIMAS E PRODUTOS TERMINADOS DA INDÚSTRIA ALIMENTÍCIA : IDENTIFICAÇÃO E PERSPECTIVAS DE CONTROLE
}

\author{
LUIZ EDIARDO LEITESHAVES \\ Engenheiro Agrônomo
}

Orientador: Prof. Dr. EVONEO BERTI FILHO

Tese apresentada à Escola Superior de Agricultura
"Luiz de Queiroz", Universidade de São Paulo,
para a obtenção do título de Doutor em Ciências.
Área de concentração : Entomologia

PIRACICABA

Estado de São Paulo - Brasil

Maio - 1998 


\section{Dados Internacionais de Catalogação na Publicação (CIP) DIVISĀo DE BIBLIOTECA E DOCUMENTAÇĀO - Campus "Luiz de QUeirOZ"/USP}

Chaves, Luiz Eduardo Leite Artrópodos presentes em caminhóes que transportam matérias-primas e produtos serminados da indústria alimenticia: identificaçăo e perspectivas de controle / Luiz Eduardo Leite Chaves. - - Piracicaba, 1998.

78 p. : il.

Tese (doutorado) - Escola Superior de Agricultura Luiz de Queiroz, 1998. Bibliografia.

1. Artrópode-vetor-de-doença 2. Biossegurança 3. Caminhăo 4. Indústria alimenticia 5. Praga urbana 6. Produto alimenticio 7. Transporte 1. Titulo 
À minha esposa

Anne, pela ajuda, apoio, compreensão e caninho

e aos meus pais, Sebastião e Maria Emília

pelo constante incentivo,

DEDICO 


\section{AGRADECIMENTOS}

O autor deseja agradecer a todos que direta ou indiretamente contribuíram para a realização desta pesquisa, em especial:

A Deus, que sempre esteve comigo e me permitiu vencer obstáculos

Ao Dr. Evoneo Berti Filho, Professor Associado do Departamento de Entomologia da ESALQ/USP, pelo exemplo, orientação, incentivo e principalmente pela amizade dispensada durante todos os anos que tivemos a oportunidade de trabalhar juntos.

Aos Professores e funcionários do Departamento de Entomologia da ESALQ/USP, pelos ensinamentos e consideração.

À Microbiotécnica Saneamento Ltda, principalmente à diretoria na pessoa do Sr. Roberto Thomé de Souza, pelo apoio e liberação durante os períodos das disciplinas e desenvolvimento deste levantamento.

À CAPES pela concessão de bolsa de estudos.

A todas as empresas que gentilmente cederam seus caminhões e suas instalações para a execução das amostragens . 
À Alexandra Sring, pesquisadora do Departamento de Entomologia da Virginia Polytechnic Institute \& State University (EUA) pelos inúmeros contatos, sugestões de literaturas e fornecimento de endereços de entomologistas que pudessem auxiliar-me em meu levantamento.

Ao inúmeros pesquisadores que gentilmente responderam às minhas mensagens, cujas sugestões foram de grande valia para o delineamento desta pesquisa.

Aos funcionários da Biblioteca Principal da ESALQ/USP e das Bibliotecas dos Departamentos de Entomologia e Fitopatologia da Minnessota University, Campus de Saint Paul (EUA), pelo tempo e atenção dispensada durante a execução de minha revisão bibliográfica.

Aos colegas do curso de Pós-Graduação, pela amizade, horas de estudo coletivo e bons momentos vividos.

Ao técnicos agrícolas e colegas de trabalho, Jefferson Fernando Rodrigues e Leandro Augusto Ferreira pela ajuda e cooperação durante as amostragens nos caminhões. 


\section{SUMÁRIO}

Páginas

LISTA DE FIGURAS .................................................................. vi.

LISTA DE TABELAS ....................................................................... ix.

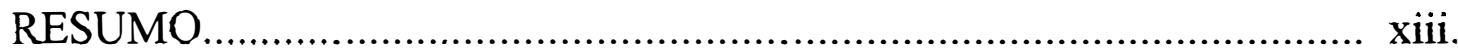

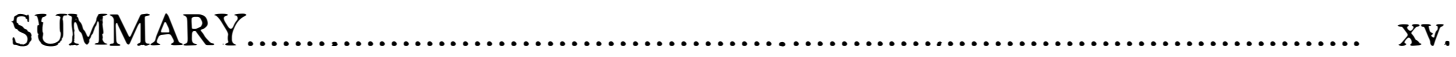

1. INTRODUÇÃO ............................................................. 1

2. REVISÃO DE LITERATURA. ................................................. 3

3. MATERIAL E MÉTODOS. ................................................... 10

3.1. Amostragem........................................................... 10

3.2. Identificação do material coletado....................................... 16

4. RESULTADOS E DISCUSSÃO............................................. 20

4.1. Amostragem............................................................... 20

4.2. Artrópodos amostrados.................................................. 23

4.3. Comparação entre carrocerias baú e lonadas ........................ 39

4.4. Possibilidades de controle....................................................... 46

5. CONCLUSÕES.................................................................. 50

6. BIBLIOGRAFIA CONSULTADA ........................................... 51

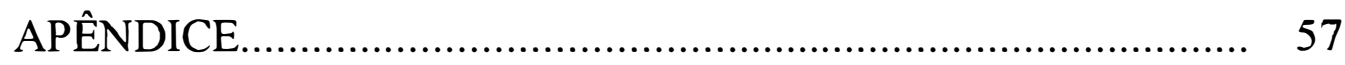




\section{LISTA DE FIGURAS}

Página

1. Caminhão estacionado em uma doca de fábrica, local onde foi realizada grande parte das amostragens............................ 11

2. Caminhão baú onde se realizaram as amostragens.

3. Caminhão lonado onde se realizaram as amostragens

4. Aspirador de pó elétrico utilizado para

a realização das amostragens das carrocerias dos

caminhões.

5. Exemplo do filtro de papel descartável utilizado para a coleta individualizada das amostras das carrocerias dos caminhões . A dobrado, e com as anotações pós aspiração, e B vazio, anteriormente à aspiração

6. Detalhe de frestas e fendas existentes no. interior das carrocerias dos caminhões, onde se procurou dar maior ênfase durante as amostragens.

7. Borrachas de vedação das portas de caminhões baú que podem abrigar populações de Blattella germanica (Blattodea : Blattellidae) 
8. Chapas de compensado de madeira que freqüentemente são utilizadas para a proteção do piso de carrocerias baú

9. Exemplo de "pallets" de madeira que são utilizados em indústrias de alimentos, e que apresentam grande potencial para transporte de artrópodos das fábricas para os caminhões e destes para as fábricas

10. Papelão comumente encontrado em carrocerias de caminhões baú 28

11. Travessas e compensados de madeira que podem abrigar colônias de cupins do gênero Cryptotermes (Isoptera : Kalotermitidae) no interior de carrocerias de caminhões. 34

12. Carroceria de caminhões lonados que podem abrigar colônias de cupins do gênero Cryptotermes (Isoptera : Kalotermitidae).

13. Detalhe da presença de poeira e resíduos oriundos de antigos transportes nas carrocerias de caminhões baú

14. Porcentagem das amostras de caminhões lonados, baú e de caminhões em geral contendo fragmentos de insetos.

15. Porcentagem de amostras de caminhões baú, lonados e de caminhões em geral contendo insetos da Ordem Psocoptera. 
viii.

16. Porcentagem de amostras de caminhões baú, lonados e de caminhões em geral contendo ácaros.

17. Relação entre o total de amostras e o número de insetos por Ordens, amostrados em caminhões lonados 44

18. Relação entre o total de amostras e o número de insetos por Ordens, amostrados em caminhões

baú 45 


\section{LISTA DE TABELAS}

Página

1. Artrópodos e fragmentos de insetos $(\mathrm{F})$ encontrados nas amostras (A) realizadas em caminhões (C) lonados (L) e baú(B), na região metropolitana de São Paulo de outubro a 1996 e outubro de 1997. Valores observados entre parênteses representam o número de indivíduos. A letra $\mathrm{m}$ indica que os indivíduos amostrados estavam mortos

2. Total de indivíduos $(\mathrm{N})$ coletados em amostras provenientes de carrocerias de caminhões realizadas na região metropolitana de São Paulo, de outubro de 1996 a outubro de 1997. Porcentagem de indivíduos frente ao total $(\% \mathrm{~N})$, freqüência $(\mathrm{F})$, porcentagem de indivíduos vivos $(\% \mathrm{NV})$; porcentagem das amostras contendo indivíduos (\%AN), e constância (C) 68

3. Indivíduos $(\mathrm{N})$ coletados em amostras provenientes de carrocerias de caminhões realizadas na região metropolitana de São Paulo, de outubro de 1996 a outubro de 1997. Porcentagem de indivíduos 
frente ao total $(\% \mathrm{~N})$, freqüência $(\mathrm{F})$, porcentagem de indivíduos vivos (\%NV); porcentagem das amostras contendo indivíduos (\%AN) e constância (C).

Primeira avaliação

4. Indivíduos $(\mathrm{N})$ coletados em amostras provenientes de carrocerias de caminhões realizadas na região metropolitana de São Paulo, de outubro de 1996 a outubro de 1997. Porcentagem de indivíduos frente ao total $(\% \mathrm{~N})$, freqüência $(\mathrm{F})$, porcentagem de indivíduos vivos (\%NV); porcentagem das amostras contendo indivíduos (\% AN) e constância (C). Análise após setenta dias de quarentena.

5. Indivíduos $(\mathrm{N})$ coletados em amostras provenientes de carrocerias de caminhões baú, realizadas na região metropolitana de São Paulo, de outubro de 1996 a outubro de 1997. Porcentagem de indivíduos frente ao total $(\% \mathrm{~N})$, freqüência $(\mathrm{F})$, porcentagem de indivíduos vivos (\%NV); porcentagem das amostras contendo indivíduos (\%AN) e constância (C) 
6. Indivíduos $(\mathrm{N})$ coletados em amostras provenientes de carrocerias de caminhões baú, realizadas na região metropolitana de São Paulo, de outubro de 1996 a outubro de 1997. Porcentagem de indivíduos frente ao total $(\% \mathrm{~N})$, freqüência $(\mathrm{F})$, porcentagem de indivíduos vivos (\%NV); porcentagem das amostras contendo indivíduos (\%AN) e constância (C). Primeira avaliação

7. Indivíduos $(\mathrm{N})$ coletados em amostras provenientes de carrocerias de caminhões baú, realizadas na região metropolitana de São Paulo, de outubro de 1996 a outubro de 1997. Porcentagem de indivíduos frente ao total $(\% \mathrm{~N})$, freqüência $(\mathrm{F})$, porcentagem de indivíduos vivos (\%NV); porcentagem das amostras contendo indivíduos (\%AN) e constância $(\mathrm{C})$. Análise após 70 dias de quarentena

8. Indivíduos $(\mathrm{N})$ coletados em amostras provenientes de carrocerias de caminhões lonados, realizadas na região metropolitana de São Paulo, de outubro de 1996 a outubro de 1997. Porcentagem de indivíduos frente ao total 
$(\% \mathrm{~N})$, freqüência $(\mathrm{F})$, porcentagem de indivíduos vivos (\%NV); porcentagem das amostras contendo indivíduos (\%AN) e constância (C). 78

9. Indivíduos $(\mathrm{N})$ coletados em amostras provenientes de carrocerias de caminhões lonados realizadas na região metropolitana de São Paulo, de outubro de 1996 a outubro de 1997. Porcentagem de indivíduos frente ao total $(\% \mathrm{~N})$, freqüência $(\mathrm{F})$, porcentagem de indivíduos vivos (\%NV); porcentagem das amostras contendo indivíduos (\%AN) e constância (C). Primeira avaliação.

10. Indivíduos $(\mathrm{N})$ coletados em amostras provenientes de carrocerias de caminhões lonados, realizadas na região metropolitana de São Paulo, de outubro de 1996 a outubro de 1997. Porcentagem de indivíduos frente ao total $(\% \mathrm{~N})$, freqüência $(\mathrm{F})$ porcentagem de indivíduos vivos $(\% \mathrm{NV}) ;$ porcentagem das amostras contendo indivíduos (\%AN) e constância (C). Análises após 70 dias de quarentena 


\title{
ARTRÓPODOS PRESENTES EM CAMINHÕES QUE
} TRANSPORTAM MATÉRIAS-PRIMAS E PRODUTOS TERMINADOS DA INDÚSTRIA ALIMENTÍCIA : IDENTIFICAÇÃO E PERSPECTIVAS DECONTROLE

\author{
Autor: LUIZ EDUARDO LEITE CHAVES \\ Orientador: Prof. Dr. EVONEO BERTI FILHO
}

\section{RESUMO}

Com o objetivo de constatar a presença de artrópodos no interior de caminhões que transportam matérias-primas e produtos terminados para a indústria alimentícia, foi realizado este levantamento dos meses de outubro de 1996 a outubro de 1997. Aspirou-se 271 carrocerias vazias de caminhões, sendo 224 baú e 47 lonados, cujo tempo variou em relação à metragem cúbica dos compartimentos. Cada amostra foi analisada visualmente e estereoscopicamente 24 horas e 70 dias após sua coleta. Os indivíduos coletados foram identificados, quando possível, e submetidos à análise faunística de freqüência e constância. Os resultados apontaram a aspiração como procedimento válido a ser incorporado pelas indústrias para avaliações rápidas da ocorrência de artrópodos em carrocerias, 
sendo que estas apresentaram-se bastante propícias à entrada desses animais. Insetos da Ordem Psocoptera foram freqüentes, e ácaros constantes. Carrocerias baú mostraram-se ambientes de maior potencial para abrigar insetos e aracnídeos quando comparadas às carrocerias lonadas. Como prática de controle, a limpeza criteriosa e freqüente apresentou-se como a alternativa mais viável e que tende a apresentar melhores resultados para a retirada de artrópodos acidentais e evitar a possibilidade de desenvolvimento destes em seu interior. 


\title{
ARTHROPODS IN TRUKS TRANSPORTING RAW MATERIAL AND PROCESSED PRODUCTS OF THE FOOD INDUSTRY: IDENTIFICATION AND PERSPECTIVES OF CONTROL.
}

\author{
Author : LUIZ EDUARDO LEITE CHAVES \\ Adviser : Prof. Dr.EVONEO BERTI FILHO
}

\section{SUMMARY}

To evaluate the occurrence of arthropods in trucks transporting raw material and processed products of the food industry, a survey was carried out between October 1996 and October 1997 in those vehicles. As a sampling methodology it was used the sucking process in 271 empty coachworks of the van type and canvas covered trucks. The sucking time varied according to the footage of the coachworks. Each sample was visually and stereoscopically analysed 24 hours and 70 days after being taken. The specimens collected were identified whenever possible and submitted to faunistic analysis of frequence and constancy. The results have indicated the sucking method as a valid procedure which should be adopted by the food industry for quickly 
evaluating the occurrence of arthropods inside truck coachworks. Insects of the Order Psocoptera were frequent and mites were constant. Coachworks of the van type presented higher potential for sheltering insects and spiders when compared to the canvas covered coachwork. Frequent cleaning is the best alternative to remove arthropods and prevent their development inside coachworks. 


\section{INTRODUÇÃO}

Qualidade, nos últimos anos, tornou-se um dos principais objetivos no estilo de vida da sociedade moderna. Para isso, moradia, vestimenta, saúde e, principalmente, alimentação vêm passando por rígidos sistemas de avaliação e discussão, onde a problemática relativa a artrópodos adquiriu "status" bastante peculiar.

Anos atrás, conviver com pequenos insetos em residências, escritórios ou qualquer outro local onde existisse atividade humana era considerado, se não admissível, tolerável.

Hoje, este enfoque mudou bastante. Os antigos problemas entomológicos com vetores de moléstias tropicais como malária, dengue e outras enfermidades em regiões endêmicas ou com potencial para isso, vêm sendo somados a outros até então muito pouco estudados: baratas agindo como agentes de contaminações de alimentos por microrganismos oriundos de esgotos ou pontos contendo resíduos indesejáveis (Gordon, 1996), formigas atingindo importância primána como fonte de infecções hospitalares (Service, 1996), ácaros domiciliares acarretando ou agravando problemas respiratórios em seres humanos (Walker, 1994), além de carunchos e traças depreciando produtos alimentícios embalados, gerando conseqüente impossibilidade de consumo (Bauer, 1985 ; Hill, 1990). 
Face a tal problemática, programas de controle de artrópodospraga em áreas urbanas passaram a ser desenvolvidos em quase todas as empresas fornecedoras de matérias-primas, transformadoras, armazenadoras ou comercializadoras de produtos alimentícios manufaturados. Aparentemente, toda a cadeia economicamente ativa de alimentos processados e consumidos em áreas urbanas possui alguma atividade visando eliminar suas presenças. A este conjunto de ações, que visa impedir a chegada de insetos ou microrganismos às fabricas, através de ações preventivas em fornecedores, denomina-se "Biossegurança" (Troller, 1983).

Contudo, o transporte, a principal ligação entre os inúmeros elos dessa cadeia produtiva, que no Brasil é basicamente feito por caminhões, até hoje nunca recebeu a atenção necessária quanto à presença de insetos e aracnídeos em seu interior, os quais podem estar gerando infestações cruzadas entre produtos absolutamente diversos, prejudicando assim seu aspecto, sanidade e até a imagem corporativa da respectiva empresa.

Mediante tal hipótese, o objetivo deste trabalho foi constatar e identificar, através de amostragens, a ocorrência de artrópodos no interior de caminhões que transportam matérias-primas e produtos terminados da indústria alimentícia, além de obter subsídios para o desenvolvimento de práticas de controle preventivas e/ou curativas. 


\section{REVISÃO DE LITERATURA}

Dole \& Maddison (1984) estudaram a dispersão de insetos e sua relação com meios de transporte, na região do Pacífico Sul. Inicialmente os autores relataram que determinados comportamentos e hábitos alimentares de insetos podem permitir maior ou menor capacidade de dispersão, como: insetos que apresentam maior capacidade de permanência em vôo são mais facilmente conduzidos por correntes de ar, atingindo assim pontos mais distantes; insetos polífagos se dispersam mais facilmente que outros com espectro de alimentação mais restrito etc. Contudo, apontaram a atividade humana como o principal agente de dispersão de insetos, destacando que, após a popularização do uso de navios e aviões para o transporte comercial e o aumento das malhas ferroviárias e rodoviárias, os problemas de introdução de espécies de insetos alóctones aumentaram significativamente, justificando os sofisticados sistemas de quarentena e segurança fitossanitária existente nos diferentes países.

Armitage et al. (1994) descreveram que insetos podem estar associados aos meios de transporte, e que perdas econômicas a estes relacionadas não se limitam apenas aos danos causados pelas respectivas atividades de consumo e excreção, mas também pelo risco de contaminação proveniente de excessivas ou descuidadas ações de controle. O uso de 
tratamentos químicos profiláticos pode resolver o problema relativo à presença específica da praga, mas o risco da ocorrência de resíduos, principalmente em alimentos, tende a reduzir ao máximo os limites e as permissões de tais atividades de controle. Assim, Troller (1983) destacou que estratégias de Manejo Integrado de Pragas devem cada vez mais ser aceitas e utilizadas em ambientes urbanos produtivos, principalmente na indústria de alimentos.

Cooley (1993) definiu Manejo Integrado de Pragas como a forma de determinar quão sério é um problema e que alternativas são cabíveis para cada situação, visando a tomada de decisão sobre determinada atividade de controle. Para isso, é fundamental conhecer profundamente o material em questão, as pragas envolvidas e o meio a ser trabalhado antes de qualquer ação.

É justamente na necessidade de adequação às práticas de Manejo Integrado de Pragas que vêm sendo utilizadas na área urbana que Robinson (1996) destacou os meios de transporte como lacunas, principalmente no desconhecimento das pragas infestantes, visto ser escassa a literatura relativa à presença, estudos ou avaliações de insetos nestes ambientes.

Segundo Schoenherr \& Rutledge (1991), insetos-praga associados a meios de transporte podem ser classificados em três gnupos:

- pragas primárias - aquelas que se alimentam e se reproduzem em produtos transportados ou no interior de meios de transporte e que causam prejuízo aos produtos; 
- pragas secundárias - aquelas que não se alimentam e não se reproduzem em produtos transportados, mas cuja presença pode indicar falta de condições higiênicas associadas ao material transportado, ou mesmo seu suposto estado de decomposição;

- pragas acidentais - são insetos que podem entrar em carrocerias de veículos por acaso e neles permanecer confinados, sem gerar qualquer prejuizo direto ao material.

Schoenherr \& Rutledge (1991) apontaram, ainda, a identificação das espécies envolvidas como base de um perfeito diagnóstico dos problemas existentes e estudo de suas soluções. Isto é importante, principalmente na análise de riscos da presença de artrópodos junto à carga transportada. Como exemplo, se há desconhecimento dos efetivos riscos à qualidade e das legislações relativas ao problema, cargas inteiras podem ser descartadas por inspetores despreparados, devido a presença de um único inseto na carroceria, mesmo que este inseto possa não representar qualquer prejuízo à qualidade do material transportado.

Mallis (1990) descreveu que muitos meios de transporte estão sujeitos à invasão por insetos. Em sua revisão sobre o assunto, apontou principalmente para os maiores problemas existentes em aviões: pulgas e Blattella germanica (Blattodea : Blattellidae). Os mais prováveis pontos de acesso desses insetos ao interior de aviões também foram citados: papelão utilizados em embalagens, cargas em geral, módulos de alimentação, acesso via piso no momento do carregamento e da entrada de passageiros, e mesmo a entrada acidental através das portas, quando em solo. 
Dole \& Maddison (1984) também descreveram o momento do carregamento e descarregamento de meios de transporte como sendo os principais momentos de infestação por insetos, principalmente à noite e próximo de iluminação branca ou incandescente. Para isso recomendaram constante limpeza e inspeção de áreas adjacentes ao carregamento, como docas, rampas, ou onde carrocerias ou "containers" possam permanecer abertos.

Davis (1991) caracterizou ser quase impossível criar sistemas que venham a garantir ambientes urbanos totalmente livres de insetos. Isso se explica pela dificuldade de se desenvolver trabalhos de sanitização, limpeza e eliminação de pontos de penetração de insetos, do meio externo para o interior do ambiente em questão, que atuem com $100 \%$ de eficiência. O autor apontou a habilidade de detectar defeitos em sistemas como a principal atividade no controle de pragas urbanas, visto que a total dependência da utilização de tratamentos químicos é uma prática não mais recomendada e tendendo ao desuso. Assim, caminhões que servem a quase todos os sistemas de produção industrial ou distribuição de artigos da economia primária apresentam-se como ambientes que necessitam tanto da ausência de insetos como da não permanência de residual de inseticidas, quando de sua utilização.

Hederson \& Meinster (1977) relataram que o potencial de contaminação de alimentos transportados é maior em caminhões, quando comparado a trens, nos Estados Unidos. Alimentos processados são geralmente transportados em carrocerias fechadas. Veículos abertos são utilizados para vegetais frescos, animais vivos ou grãos. O fato de haver 
grande diversidade de produtos carregados pela mesma carroceria, procedentes de locais e ambientes diferentes, caracteriza a necessidade de efetivas práticas de limpeza. Embora se preconize grande cuidado nesse procedimento, normalmente ele é insuficiente para eliminar todos os resíduos procedentes do transporte, mantendo condições não só para a proliferação como para a atração de insetos. Algumas carrocerias podem passar apenas por limpezas de rotina, que já são suficientes para assegurar a carga. Em outros casos há a necessidade da combinação de limpeza com utilização de inseticidas para tal garantia, os quais podem ser de ação residual ou não, dependendo da carga, do intervalo de tempo entre carregamentos ou do início do transporte, além da possibilidade de penetração de insetos no sistema durante o tempo de transporte.

Jay et al. (1983) descreveram que a metodologia de controle químico de insetos, mais comumente utilizada em carrocerias vazias de caminhões, é a fumigação através de fosfeto de alumínio ou magnésio, inclusive podendo ser realizada em caminhões em trânsito, desde que sejam respeitados determinados procedimentos de segurança tais como: hermeticidade do "container" ou máximo de vedação, assegurar-se que não existe a possibilidade de entrada de água no ambiente, que as paradas do caminhão ocorram sempre em locais abertos, ventilados e distantes de ambientes habitados, além de respeitar o tempo mínimo de exposição ao gás.

Para Halliday et al. (1987), o ideal seria o uso exclusivo de inseticidas para o controle de focos de insetos, determinados por inspeções, e depois eliminação das aberturas existentes nas carrocerias. Caminhões baú 
normalmente demonstram melhores condições de isolamento do sistema interno com o meio exterior. Alguns, por possuírem ambiente refrigerado, ou mesmo atmosfera controlada, condições estas necessárias para 0 transporte de determinados materiais, apresentam-se bastante difíceis a penetrações de insetos. Contudo, ao se realizarem fumigações ou termonebulizações em seu interior, comumente identifica-se a liberação de gases, indicando a não existência da hermeticidade preconizada.

Por isso, a necessidade de rotinas de inspeções minuciosas das carrocerias dos caminhões torna-se muito importante. Holman (1991) descreveu procedimentos gerais de inspeção em indústrias alimentícias a partir de uma revisão de normativas da "Food and Drug Administration" (FDA) e do "United States Department of Agriculture" (USDA). O autor relacionou itens a serem observados durante uma inspeção em caminhões: tipo de carga e destino anterior à inspeção, estado de limpeza e conservação da carroceria, pontos de ferrugem, mofo, presença de insetos vivos ou mortos, se houve fumigação ou não da carroceria e se todas as aberturas estão suficientemente vedadas para impedir a entrada de insetos. Contudo, nenhum procedimento padrão para inspecionar veículos de transporte, a não ser observação visual, foi citada. Sugeriu-se apenas que qualquer metodologia empregada deve estar de confonmidade com os objetivos da inspeção, a qual pode variar de inspetor para inspetor.

Relativo à aspiração, inúmeras são as citações que destacam esta metodologia como indicada para amostragem de artrópodos na agricultura, como Nakano et al, 1981; Bauer, 1985; Benett et al. 1988; MuirheadThomson, 1991; Erishman, 1994 e Pedigo \& Buntin, 1994. Contudo, 
nenhuma referência bibliográfica que a utilizasse para avaliações ou estudos entomológicos em meios de transporte foi encontrada. 


\section{MATERIAL E MÉTODOS}

\subsection{Amostragem}

A coleta dos dados foi realizada de outubro/96 a outubro/97. Foram amostrados 271 caminhões vazios, que estavam estacionados em docas de 19 empresas (Figura 1) compreendidas entre indústrias alimentícias, transportadoras e supermercados. Visou-se apenas caminhões que estivessem transportando produtos manufaturados de gêneros alimentícios como biscoitos, pães, torradas, macarrão etc, e suas respectivas matérias-primas. Contudo, excluiu-se aqueles que estavam carregando grãos "in natura" ou farinhas no momento da amostragem, por apresentarem maiores condições de conter artrópodos em seu interior, e poderem gerar distorções na análise final.

Amostrou-se os seguintes modelos de caminhões: baús, 224 unidades (Figura 2) e lonados, 47 unidades (Figura 3). Caminhões refrigerados inicialmente foram alvo de amostragens; contudo, pela dificuldade de sua obtenção, adequação à metodologia empregada e conseqüente liberação por parte das empresas, o número de amostras foi bastante reduzido, o que resultou no descarte das mesmas. 


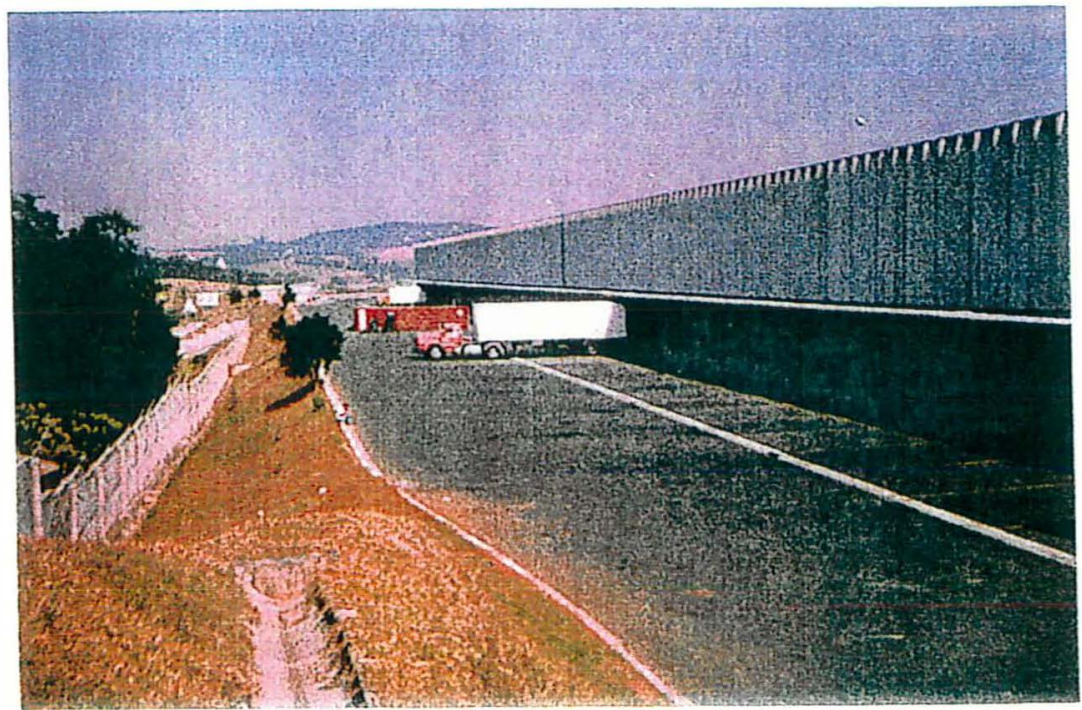

Figura 1: $\quad$ Caminhão estacionado em uma doca de fábrica, local onde foi realizada grande parte das amostragens.

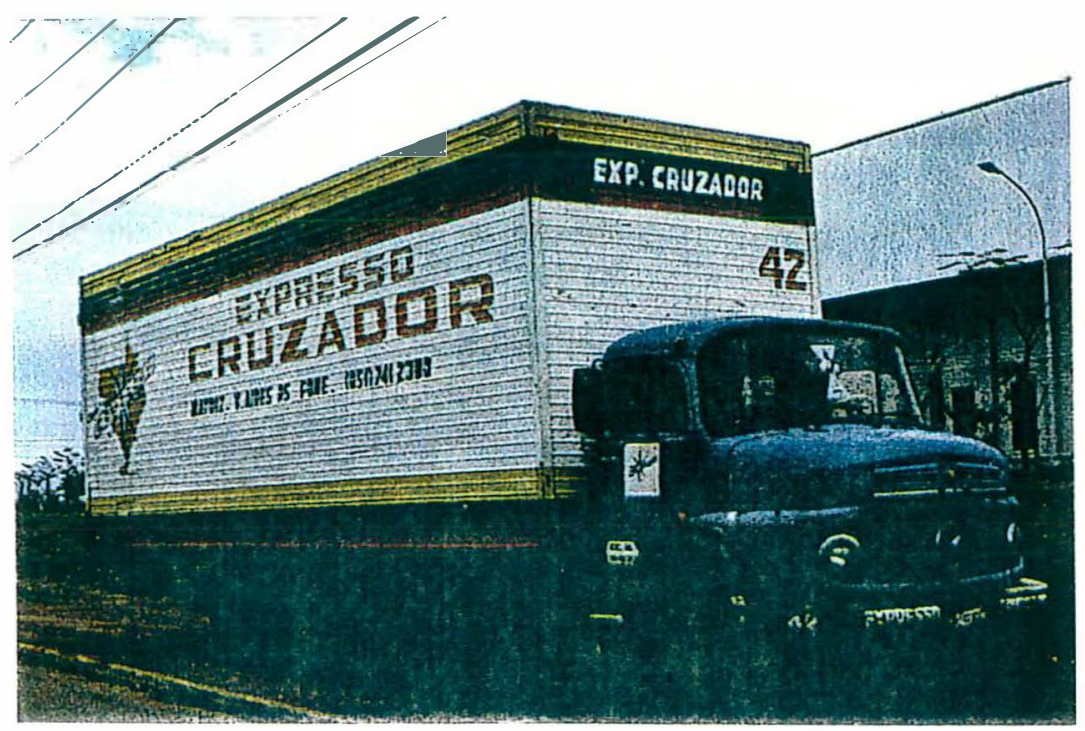

Figura 2: $\quad$ Caminhão baú onde se realizaram as amostragens. 


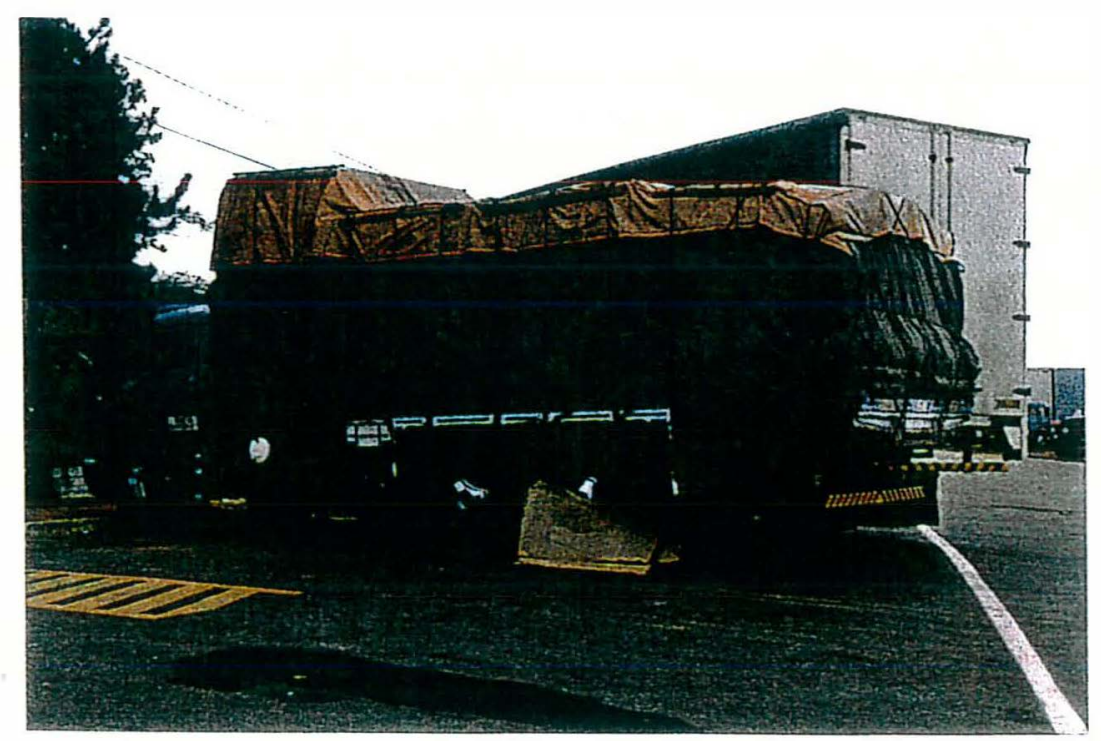

Figura 3: $\quad$ Caminhão lonado onde se realizaram as amostragens.

Cada caminhão teve sua carroceria medida com uso de trena, nas dimensões do comprimento e largura. Estas medidas, multiplicadas entre si, representaram a metragem quadrada da mesma. Para se obter a metragem cúbica amostrável de caminhões baú, multiplicou-se os valores das metragens quadradas pela distância de 2 metros, determinando assim a altura máxima até onde ocorreram as avaliações.

Caminhões lonados tiveram as alturas de suas carrocerias totalmente medidas, não sendo utilizado $2 \mathrm{~m}$ para obter sua respectiva metragem cúbica, visto serem normalmente baixas e viabilizar amostragem em sua totalidade.

Desta forma foi possível uniformizar a obtenção dos volumes de cada carroceria de caminhões, sejam baús (máximo $2 \mathrm{~m}$ de altura) ou lonadas. Com estes valores, estipulou-se que para cada $20 \mathrm{~m}^{3}$ seriam 
despendidos 60 segundos (1 minuto) de amostragem. Com tal adequação, independente do tamanho das carrocerias, foi possível utilizar tempos proporcionais à sua respectiva metragem cúbica, podendo-se assim efetuar comparações entre caminhões de diferentes tamanhos. Para isso utilizou-se um cronômetro de pulso.

Ajustado o tempo de amostragem, iniciou-se sua realização propriamente dita. Esta foi efetuada através de aspiração, metodologia considerada adequada para a inspeção de grandes superfícies contendo frestas e fendas, onde amostragens visuais podem acarretar sérios erros amostrais (Bauer, 1985 ; Benett et al. 1988 e Frishman, 1994).

Burkholder (1984) comentou que a metodologia ideal para amostragens de insetos, em meios de transporte utilizados para grãos, seria com o uso de armadilhas com feromônios. No entanto, o objetivo deste trabalho foi de conhecer quais as populações de artrópodos existentes nas diferentes carrocerias dos caminhões que transportam matérias-primas e produtos acabados para a indústria alimentícia, e para isso seria necessário um grande espectro de feromônios e respectivas armadilhas, além de tempo para que estas viessem a iniciar seu período de atração. Mediante a efetiva impossibilidade de adequar e de se conseguir armadilhas com feromônios para um grande número de espécies de insetos, optou-se pela utilização de aspirações.

Para as amostragens utilizou-se um aspirador elétrico manual ( 700 W, 220 V) (Figura 4), acompanhado de extensão elétrica, um transformador de $110 \mathrm{~V}$ para $220 \mathrm{~V}$ visando a possibilidade de utilização do aparelho em 
qualquer fonte elétrica, ou gerador elétrico $(220 \mathrm{~V})$ à gasolina para locais onde e eletricidade encontrava-se muito distante ou era ausente.

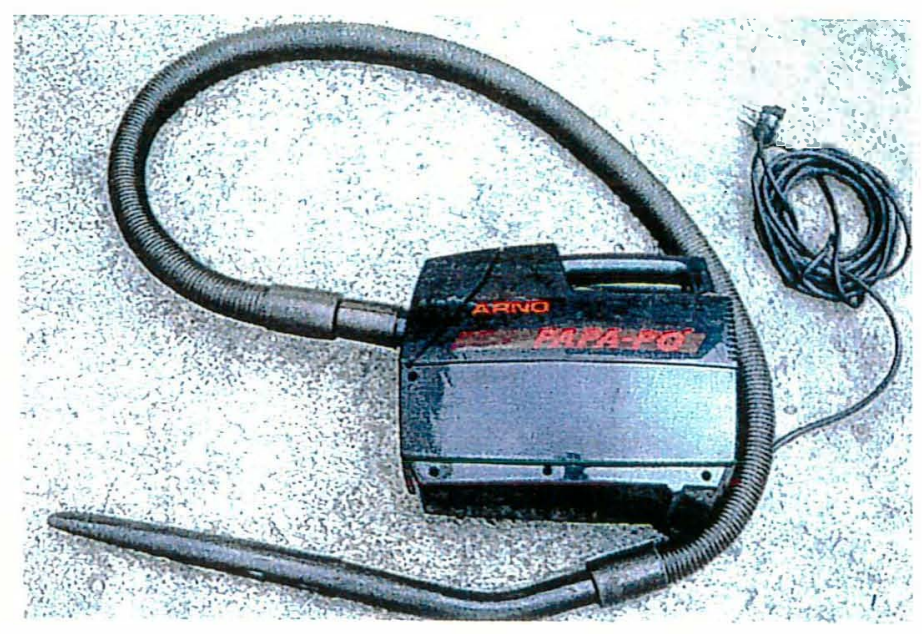

Escala 1: 8.5

Figura 4:

Aspirador de pó elétrico utilizado para a realização das amostragens das carrocerias dos caminhões.

Para cada caminhão amostrado utilizou-se um filtro de papel (Figura 5) para a coleta individualizada das amostras, evitando-se assim contaminações entre elas.

A condução do aspirador dentro das carrocerias foi ao acaso, procurando-se amostrar todos os quadrantes das mesmas, dando maior atenção para frestas e fendas (Figura 6) entre as madeiras protetoras do piso e das laterais.

Após o término de cada amostragem, retirava-se o filtro, dobravase sua extremidade aberta e grampeava-se por três vezes para evitar a fuga 


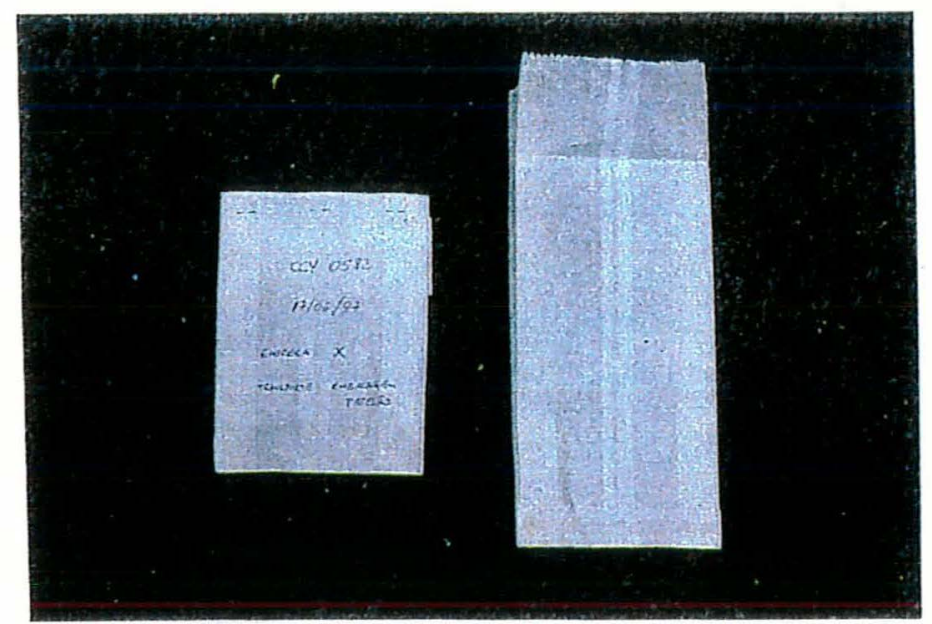

Escala $1: 5$

A

B

Figura 5:

Exemplo do filtro de papel descartável utilizado para a coleta individualizada das amostras das carrocerias dos caminhões. A dobrado, e com as anotações pós aspiração, e B vazio, anteriormente à aspiração.

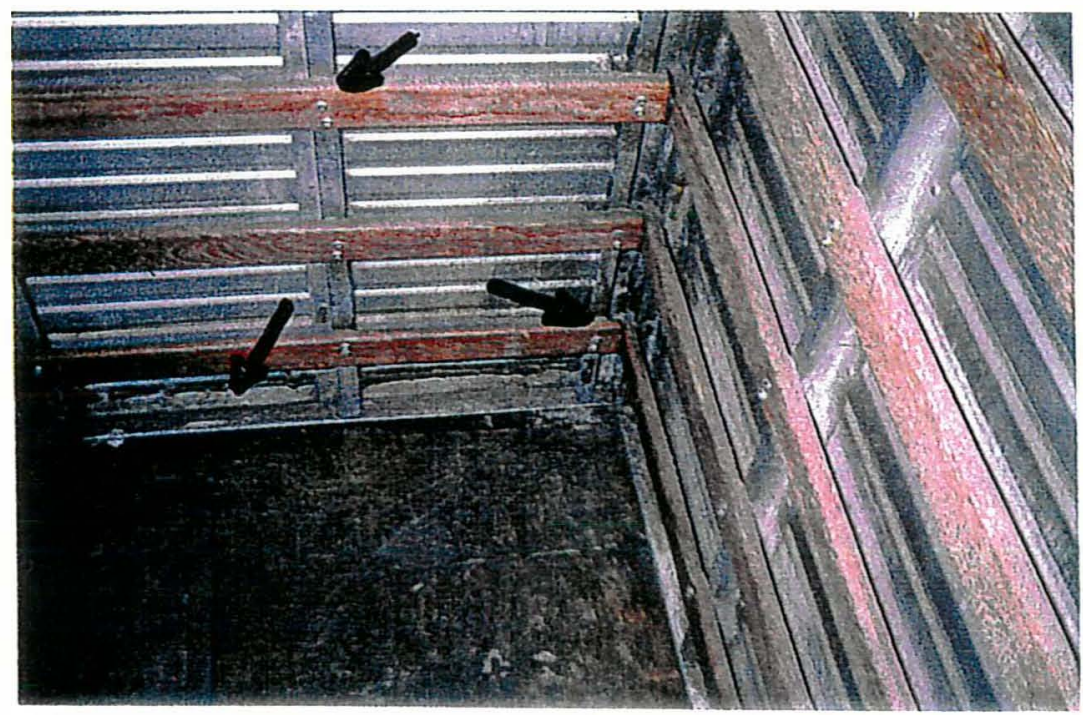

Figura 6:

Detalhe de frestas e fendas existentes no interior das carrocerias dos caminhões, onde se procurou dar maior ênfase durante as amostragens. 
de insetos ou aracnídeos vivos, ou mesmo a perda de substrato; anotava-se data, local, tipo de caminhão amostrado e respectiva numeração de placa.

Antes da instalação de novo filtro para início da próxima amostragem, deixava-se o aspirador em funcionamento por 15 segundos para a limpeza de suas estruturas fixas, como bico, mangueira etc.

\subsection{Identificação do material coletado}

As amostra foram encaminhadas à Microbiotécnica Saneamento, uma empresa especializada em controle de insetos urbanos, localizada em São Paulo SP, sendo armazenada em prateleira à temperatura ambiente. Após um período máximo de 24 horas as amostras foram retiradas do interior dos filtros de papel e expostas sobre uma pequena bandeja plástica branca, para observação visual. Para tal, utilizou-se pincel. Cada aranha ou inseto encontrado foi retirado do meio e individualizado em uma placa de petri de plástico, recebendo todos os dados contidos no filtro. Fragmentos de insetos como pedaços de abdome, asas, pernas etc, foram registrados como presença ou ausência, o mesmo ocorrendo com ácaros, os quais foram mantidos nas amostras em virtude das dificuldades existentes na sua contagem e retirada do meio.

Após a análise visual, o conteúdo restante da amostra foi transferido para o interior de uma ou mais placas plásticas de petri, conforme o volume de material coletado, onde se anotou todos os dados existentes no filtro. O material de cada placa foi submetido à análise estereoscópica em aumentos de $10 \mathrm{X}$ a $40 \mathrm{X}$ e os indivíduos encontrados receberam o mesmo tratamento citado para a análise visual. 
Após essa primeira etapa de análises, as placas de petri foram tampadas e vedadas lateralmente com fita adesiva e recolocadas em prateleira para ali permanecerem por um período de 70 dias, para posteriormente sofrerem a mesma metodologia, com as mesmas análises visuais e estereoscópicas anteriormente citadas. No interior de cada placa de petri nada foi adicionado, visando-se representar o mesmo meio existente no interior da respectiva carroceria. O objetivo dessa análise após 70 dias foi detectar insetos que estivessem em formas imaturas durante a primeira avaliação e que não puderam ser observados e consequentemente identificados. Além disso, mantido o mesmo substrato encontrado nos caminhões, pôde-se analisar também o potencial do meio amostrado no desenvolvimento de artrópodos.

Os insetos e aracnídeos encontrados, quando possível, foram identificados pelo autor até o nível de Família, utilizando-se como referências: Britton, 1973; Colless \& McAlpine, 1973; Common, 1973; Mackerras, 1973; Riek, 1973; Smithers, 1973; Hichin, 1974; Storer \& Usinger, 1979; Borror \& Delong, 1988; Gallo et al, 1988; Hill, 1990; Hedges \& Lacey, 1995 ; Pacheco \& de Paula, 1995; ou enviados para o Centro Nacional de Identificação de Insetos, na Universidade Federal do Paraná - Curitiba.

Após as observações das amostras, os dados foram analisados através dos índices faunísticos de freqüência e constância.

A análise de freqüência foi obtida somando-se os dados de todas as amostragens e calculando-se as porcentagens dos indivíduos de cada Ordem de insetos em relação ao total de indivíduos coletados (Silveira Neto 
et al. 1976). Como não foi possível realizar a contagem exata do número de aracnídeos existentes nas amostras, fato este principalmente vinculado ao grande número de ácaros e sua impossibilidade de retirada da amostra, a análise de freqüência ficou restrita às Ordens de insetos.

De acordo com os resultados obtidos, estabeleceu-se classes de freqüência em:

- pouco freqüente (pf)- Ordens de insetos cuja porcentagem se manteve abaixo da média de sua ocorrência.

- freqüentes (f) Ordens de insetos cuja porcentagem se manteve acima da média de sua ocorrência.

A análise de constância segundo Silveira Neto et al. (1976) refere-se à porcentagem de indivíduos de uma mesma Ordem, Família, Gênero ou espécie presentes nas amostragens. A fómula utilizada para o cálculo foi:

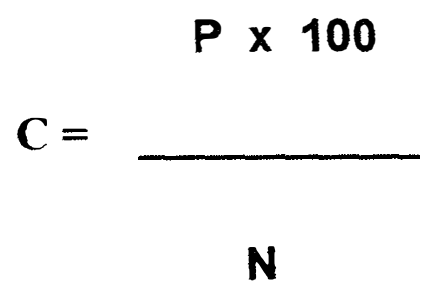

onde :

- $\quad \mathbf{P}=$ número de amostras contendo os indivíduos

- $\mathbf{N}=$ número total de amostras realizadas. 
De acordo com os percentuais obtidos, as espécies podem ser separadas em categorias, segundo classificação proposta por Bodenheimer (Silveira Neto et al. 1976):

- espécies constantes (x) - presentes em mais de $50 \%$ das amostras

- espécies acessórias (y) - presentes entre 25 e $50 \%$ das amostras

- espécies acidentais (z) - presentes em menos de $25 \%$ das amostras 


\section{RESULTADOS E DISCUSSÃO}

\subsection{Metodologia Utilizada}

Quarenta e sete caminhões lonados e 224 baús foram amostrados (Tabela 1) durante o período em questão, sendo que o número de amostras realizadas mensalmente variaram conforme a liberação dos veículos por parte das empresas avaliadas.

A metodologia amostral utilizada, a aspiração, mostrou-se parcialmente adequada para avaliações quantitativas e qualitativas.

Acredita-se que, pelo fato de $36,84 \%$ dos insetos coletados estarem mortos, e dessa forma bastante ressecados, associado ao grande volume de resíduos sólidos existentes no interior das carrocerias, como pedaços de madeira, pedras, grãos etc; durante a aspiração houve um turbilhonamento do material aspirado no interior da mangueira e do filtro do aspirador, onde o atrito dos indivíduos com as laterais do aparelho e as partículas sólidas acabou gerando quebra de muitos insetos, fato este que pode explicar a constante presença de fragmentos de insetos $(81,18 \%)$ nas amostras ( Tabela 2). 
Este fato pode ter prejudicado as avaliações qualitativas $\mathrm{e}$ quantitativas de insetos presentes nas amostras, inclusive porque se encontrou dificuldade na realização de análises taxonômicas mais detalhadas em muitos deles, visto estarem parcialmente quebrados e sem caracteres importantes para sua identificação. Dessa forma, as análises faunísticas foram desenvolvidas por Ordens de insetos e não por espécies, para melhor agrupamento.

Insetos pequenos, como psocópteros, tiveram suas contagens bastante dificultadas, ou por permanecerem aderidos ao filtro de papel utilizado na individualização das amostras, ou por ter sido muito difícil retirá-los do material aspirado, necessitando de longo tempo de observação estereoscópica para tal. No caso de ácaros, sua separação da amostra tornou-se impossível, fazendo com que a respectiva análise faunística fosse limitada apenas à constância.

Tentando avaliar possíveis frestas existentes nas carrocerias de caminhões baú, para procurar entender melhor os diferentes meios de acesso de insetos e aracnídeos para o interior dos mesmos, realizou-se um tratamento com cipermetrina a $1 \%$ de ingrediente ativo, diluída em óleo mineral e aplicada através de termonebulização em dez veículos, como descrito por Halliday et al (1987). Essa metodologia caracteriza-se pela queima de combustível através de um pequeno carburador, gerando um fluxo de gases quentes que tendem a sair por um escapamento, proporcionando variação de pressão sobre um pequeno bico, o qual permitirá o acesso da mistura óleo mineral e inseticida de um tanque anexo para o interior deste duto. A mistura até então líquida passa imediatamente para um estado semelhante à fumaça (fog), com gotas que variam de 10 a 30 
micras (Mattheus, 1982). Com tal característica física, e por estar muito mais aquecida que o ar, a mistura, quando aplicada em ambientes fechados, tende a subir e expandir, procurando pontos que permitam sua saída para o meio externo, facilitando com isso a observação de pequenos orifícios em carrocerias. Após sua realização, fechou-se a carroceria por 5 minutos e observou-se na totalidade dos veículos pequenas saídas de fumaça nas laterais da base, em alguns vértices e na junção das chapas metálicas que a constituem, permitindo entender que artrópodos podem acessar 0 interior destes ambientes facilmente através de tais frestas, caracterizando-se assim como estruturas não tão fechadas como parecem.

Além de observar as pequenas saídas de fumaça pela estrutura da carroceria, ao abrir as portas de uma delas, encontrou-se alguns exemplares de Blattella germanica (Blattodea : Blattellidae) junto ao piso. Como o caminhão amostrado era o número 90 (Tabela 1) e já havia sido amostrado anteriormente ao referido teste, pôde-se entender que a termonebulização ajudou a desalojar alguns indivíduos que estavam em frestas e que não foram capturados pela aspiração. Desta forma, uma alternativa para a metodologia utilizada seria a associação da termonebulização seguida da aspiração apenas no piso e por tempo inferior, coletando-se assim preferencialmente os insetos caídos. A vantagem seria gerar um impacto sobre insetos vivos que estivessem alojados, e consequentemente menos suscetíveis à aspiração, fazendo-os cair no piso, aumentando a eficácia da aspiração e reduzindo-se o volume de material sólido coletado, diminuindo assim o impacto deste sobre os insetos, reduzindo suas quebras e aumentando a possibilidade de identificação, como citado anteriormente. Contudo, como tal observação

ocorreu 
apenas na amostra 90, acredita-se que ensaios comparativos entre aspiração isolada e aspiração associada à termonebulização devam ser realizadas posteriormente, utilizando-se ambientes com populações previamente conhecidas e mais diversificadas que apenas $B$. germanica para aferição da metodologia ou criação de sistemas mais específicos para determinados grupos de artrópodos. Deve-se destacar que raramente é possível a utilização de termonebulização em ambientes fabris, seja pelo tempo necessário para sua aplicação, pelo barulho originado, ou por condições de segurança, onde dificilmente é possível realizar a queima de combustíveis em ambientes industriais, tornando a referida metodologia mais restrita para uso prático.

A aspiração, embora com certas limitações como anteriomente discutido, apresentou-se como excelente alternativa para inspeções práticas e rápidas das presenças de artrópodos em carrocerias de caminhões, com grande potencial de utilização em fábricas de alimentos nos momentos de recebimento de matérias-primas ou no précarregamento de produtos terminados, o que vem de encontro às citações de Bauer (1985), Benett et al. (1988) e Frishman (1994). Para estas inspeções, os analistas devem utilizar aspiradores portáteis, filtros descartáveis, pequenas bandejas brancas e lentes de aumento de $10 \mathrm{X}$ como ferramentas.

\subsection{Artrópodos amostrados}

Analisando-se os dados (Tabela 2) que representam o conjunto total das avaliações das carrocerias de caminhões, não se considerando o tipo, verificou-se que dos 299 insetos coletados, 63,16\% estavam vivos e 
$36,84 \%$ mortos. Dos insetos vivos, destaque para a Ordem Psocoptera $(59,20 \%)$, a única que se comportou como freqüente. As demais oito Ordens de insetos foram pouco freqüentes e todas, inclusive a Psocoptera, acidentais na análise faunística de constância.

Baratas, mais precisamente $B$. germanica (Blattodea : Blattellidae), que representaram 7,69 \% dos insetos coletados, sendo destes 69,56 \% vivos (Tabela 2), merecem atenção especial. Consideradas como insetos de grande capacidade de adaptação, face à sua alimentação polífaga e comportamento de alojar-se em frestas e fendas (Service, 1996), demonstraram apresentar plenas condições de colonizar o interior de caminhões baú (Tabela 5), visto somente terem sido amostradas neste tipo de carroceria. As borrachas existentes para a vedação de portas desse tipo de caminhão (Figura 7) podem abrigá-las facilmente em seu interior. Tais estruturas de vedação podem variar de formato, apresentando-se como uma mangueira, cuja abertura central pode abrigar populações de baratas, ou com dobras, dentro das quais observa-se ambiente bastante seguro para elas. Chapas de compensado de madeira encostadas à estrutura do piso das carrocerias (Figura 8) onde acumulam umidade e resíduos em sua porção inferior podem também servir como excelente abrigo para tais insetos.

Como B. germanica é cosmopolita, possue hábito de se esconder e depositar ootecas em corrugações de papelão (Mallis, 1990) e por não voar (Cornwell, 1968), pode ser facilmente conduzida para o interior de carrocerias, seja por caixas deste material, que comumente é utilizado no acondicionamento final de lotes de produtos alimentícios, ou por "pallets" (Figura 9). "Pallets” são estrados normalmente confeccionados 
em madeira, mas que também podem ser fabricados de alumínio, epoxi ou plástico, e que têm por objetivo deixar mercadorias suspensas entre $15 \mathrm{e}$ $20 \mathrm{~cm}$ do piso, além de permitirem empilhamento das mesmas e facilitar sua condução entre setores, ou nos momentos de carregamento e descarregamento através do uso de empilhadeiras. Esses estrados, sem qualquer controle, entram e saem dos mais diferentes ambientes de uma indústria e principalmente entre indústrias, tornando-se o agente com maior potencial de infestação cruzada entre empresas compreendidas na cadeia de produção, distribuição e comercialização de alimentos processados. Isso pode ser atribuído ao fato de poucas empresas possuírem rotina de limpeza dos mesmos, possibilitando que grande quantidade de resíduos permaneça em suas bases e, dessa forma, possam abrigar populações de artrópodos; devido a não inspeção ou troca dos "pallets" quando de sua chegada a um determinado setor, visto estar associado a

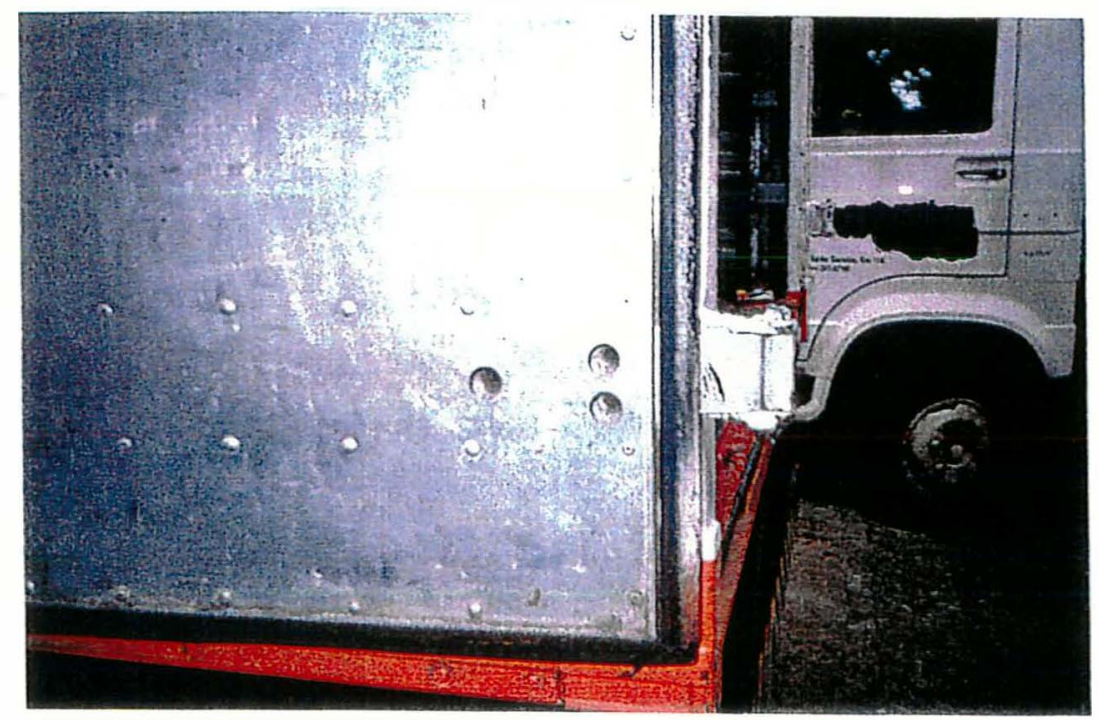

Figura 7: Borrachas de vedação das portas de caminhões baú que podem abrigar populações de Blattella germanica (Blattodea : Blattellidae) 


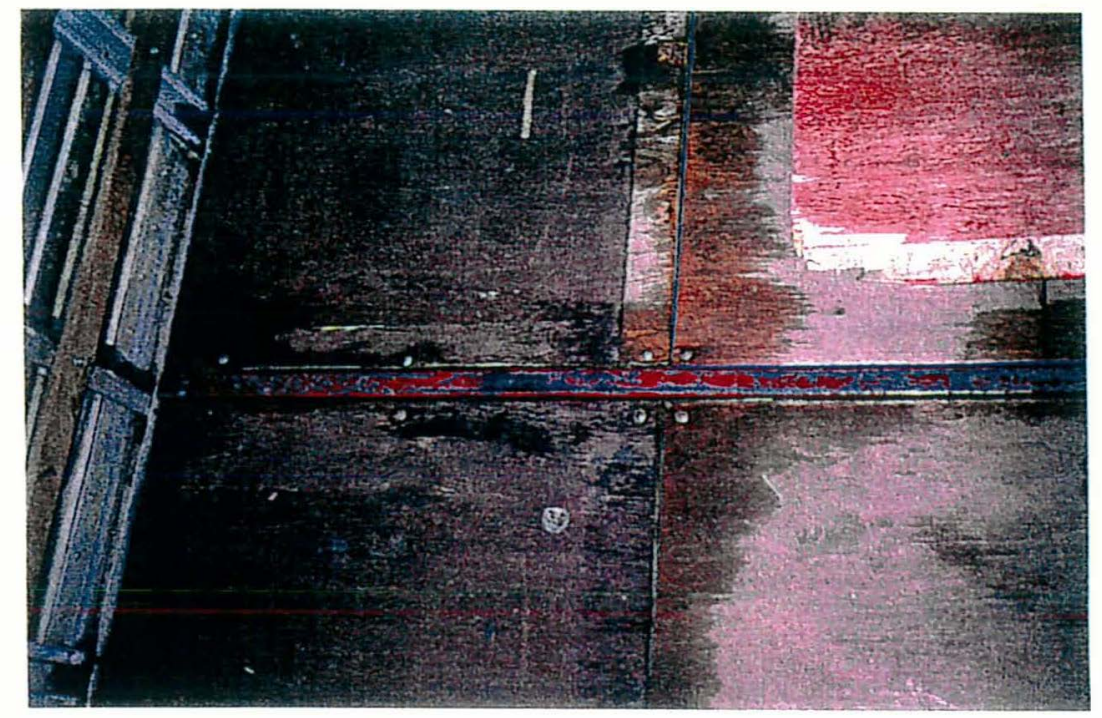

Figura 8: Chapas de compensado de madeira que freqüentemente são utilizadas para a proteção do piso de carrocerias baú.

lote de material e este estar sendo transportado por uma empilhadeira, procedimentos estes que, se alterados, dificultariam em muito a rotina operacional de uma empresa.

Os "pallets" não são apenas meios de disseminação para $B$. germanica, mas também para a grande maioria de artrópodos de hábito predominantemente terrestre, como aracnídeos, psocópteros, formigas, tesourinhas, pragas de produtos armazenados como Oryzaephilus surinamensis (Coleoptera : Silvanidae), Tribolium sp. (Coleoptera : Tenebrionidae), etc. 


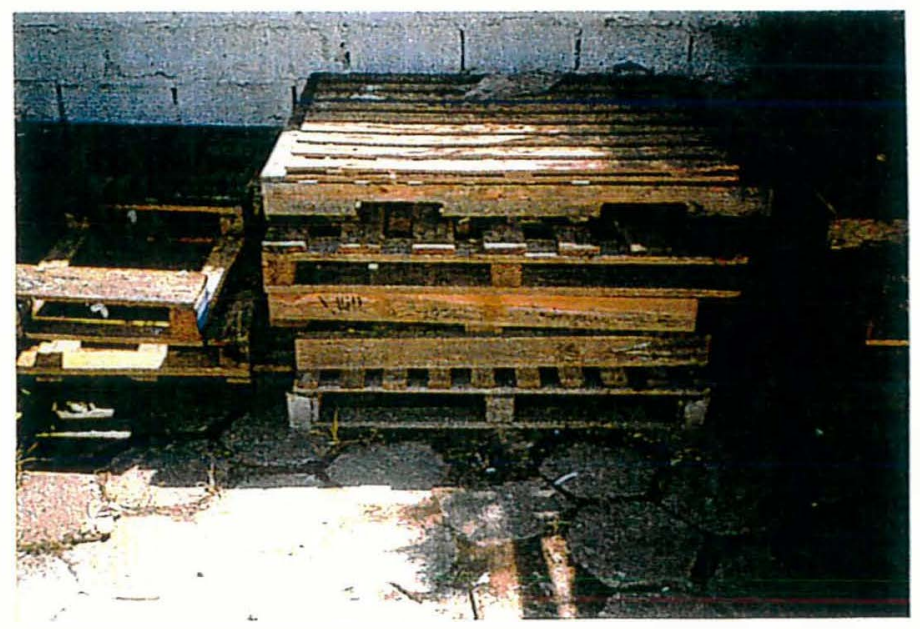

Figura 9: $\quad$ Exemplo de "pallets" de madeira que são utilizados em indústrias de alimentos, e que apresentam grande potencial para transporte de artrópodos das fábricas para os caminhões e destes para as fábricas.

Outro fator que pode facilitar a colonização por B. germanica é a permanência de chapas de papelão aderidas às paredes das carrocerias (Figura 10) para serem utilizadas como calços, as quais permitem, como citado anteriormente, abrigo e condição de colonização para a praga. Além disso, as precárias condições de limpeza, onde se pode verificar grande quantidade de resíduos que serve de alimento prontamente disponível a tais insetos, também merecem destaque. Tal disponibilidade e diversidade alimentar, adquirida através do acúmulo de materiais transportados e não retirados das carrocerias por ausência de práticas de limpeza rotineiras ou eficientes, faz com que estes insetos não tenham que se alimentar somente 
de papelão ou de cola, fato que certamente representaria uma dieta muito fraca e acabaria reduzindo seu potencial reprodutivo.

Crisomelídeos, escarabeídeos, coccinelídeos, tesourinhas, dípteros, himenópteros, homópteros e lepidópteros encontrados nas amostras comportaram-se como insetos pouco freqüentes e acidentais (Tabela 2). Embora existindo a possibilidade de entrarem nas carrocerias através de "pallets", ou juntamente com caixas oriundas de depósitos, ou mesmo junto destas quando mantidas no piso das docas anteriormente ao carregamento (Mallis, 1990), é pelo vôo que estes insetos mais facilmente acessam o interior das carrocerias de caminhões.

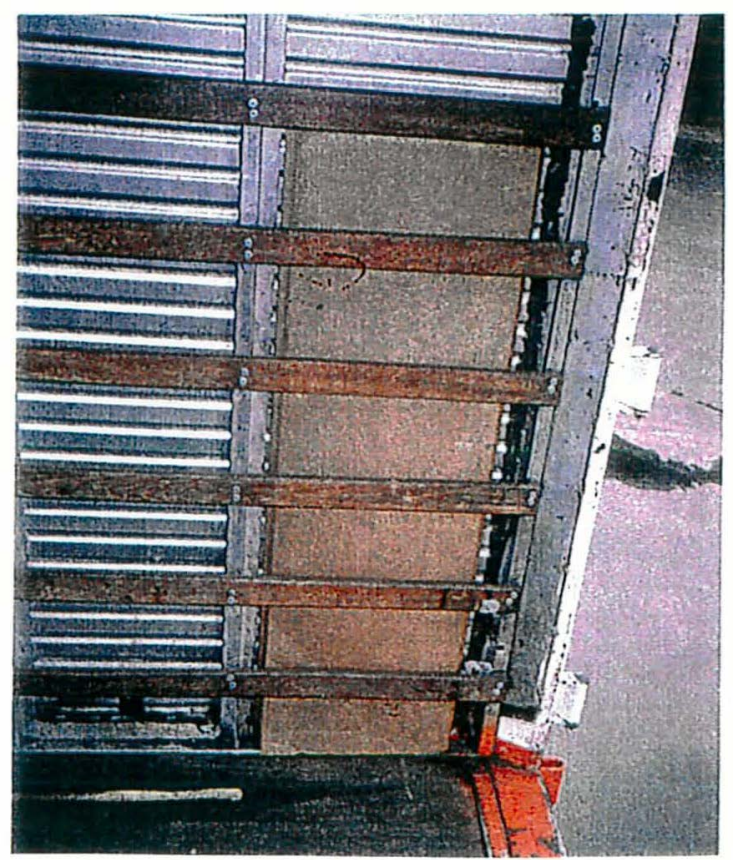

Figura 10: Papelão comumente encontrado em carrocerias de caminhões baú. 
Acredita-se que o fator de maior influência na entrada de insetos acidentais em carrocerias de caminhões baú (Tabela 5) e mesmo lonados (Tabela 8) pelo vôo é a atração luminosa existente nas docas, principalmente quando a manipulação da carga ocorre no período do crepúsculo ou à noite, conforme mencionado por Dole \& Maddison (1984). Geralmente as docas estão localizadas em ambientes abertos, livres de quaisquer proteção junto ao meio externo e, à noite ou durante o amanhecer ou entardecer, as lâmpadas, normalmente de mercúrio ou incandescentes, acabam atraindo insetos de pontos bastante distantes, os quais acidentalmente acabam adentrando nas carrocerias. Silveira Neto et al. (1976) relataram que a luz branca ou de mercúrio é rica em raios ultra-violetas, bastante atrativos a um grande número de insetos. Caso se utilizassem lâmpadas de vapor de sódio em docas externas, como proposto por Hedges (1993), tal atração seria bastante reduzida, pois o amarelo contém quantidade ínfima de raios de comprimento de onda na faixa do ultra violeta em sua composição.

Outras altemativas para a redução da incidência de insetos, que através de vôo adentram nas carrocerias de caminhões, seriam a integração de horários de carga e descarga com luzes de vapor de sódio e barreiras físicas ou mecânicas, que impedissem tais acessos. A construção de docas confinadas, onde portas automáticas se abririam no momento da chegada do caminhão e, posteriormente, ao fecharem, se adaptariam à altura da carroceria, deixando sua entrada confinada ao interior do armazém, seria a primeira opção. Como desvantagens, observa-se o fato de serem de tecnologia importada, com elevado custo e restrita manutenção, gerando inúmeros transtornos às empresas que as utilizam, visto que qualquer 
defeito em seu sistema de funcionamento acaba fazendo com que o conjunto deixe de operar por vários dias, deixando vulnerável não somente as carrocerias dos caminhões baú, mas também os armazéns.

A instalação de armadilhas luminosas, utilizando-se lâmpadas de ultra-violeta, associadas a mecanismos de controle de insetos à base de eletricidade ou placas adesivas (Hedges, 1993) também são alternativas interessantes para capturar insetos que estejam voando próximos às docas. Nesse caso deve-se procurar evitar instalar tais armadilhas em posições que lhes permitam fácil visualização por insetos que estejam no meio externo. Isso se explica pelo fato de tais sistemas não apresentarem $100 \%$ de capacidade de controle, possibilitando, desde que não estejam instaladas corretamente, a atração de insetos de jardins, ruas etc para o setor das docas sem a possibilidade de controlá-los totalmente, acarretando em aumento no potencial de infestação das carrocerias. Nesse sentido, deve-se dar preferência por associá-las a ambientes fechados ou parcialmente fechados.

Cortinas de ar são outro sistema de barreira para evitar o acesso de insetos ao interior de carrocerias de caminhões baú. Desde que instaladas no limite entre o final do armazém e o ponto de entrada para a carroceria dos caminhões, o fluxo de ar vertical e constante, proveniente deste sistema pode reduzir significativamente o acesso de insetos em vôo ao interior dos veículos. Bauer (1985) relatou que atenção deve ser dispensada à instalação de cortinas de ar, procurando avaliar sempre a pressão de ar gerada pelo sistema, verificando que esteja suficientemente forte até a limite do piso, visto que se isso não ocorrer, o próprio fluxo de ar acaba empurrando insetos que ali chegam para o interior do ambiente que se queira proteger. Outro aspecto levantado pelo autor é sobre o ângulo de incidência do fluxo 
de ar. Se este não estiver direcionado para fora do limite da área a ser protegida, o turbilhonamento de ar acaba envolvendo o inseto e ao entrar em contato com o piso, arrasta-o para o interior do setor, gerando assim infestações. Para isso é necessário constante regulagem das aletas existentes no corpo das cortinas para o ajuste ideal do ângulo do fluxo de ar.

Lasioderma serricorne (Coleoptera : Anobiidae) e Tribolium castaneum (Coleoptera : Tenebrionidae) podem adentrar as carrocerias por todos os processos já comentados anteriormente, mas o fato de alimentos pré-infestados contendo tais insetos serem carregados para o interior dos caminhões e, a partir desse momento, infestar a carroceria é a maior possibilidade da origem de suas presenças, o mesmo ocorrendo para outras pragas de produtos armazenados como Oryzaephilus surinamensis ( Coleoptera : Silvanidae), Gnathocerus sp. (Coleoptera : Tenebrionidae), Sitophilus sp. (Coleoptera : Curculionidae), Tribolium sp. e determinadas traças .

No caso específico de Sitophilus $s p$. pôde-se comprovar tal hipótese. Uma única amostra, o caminhão número 187 (Tabela 1) continha 2 adultos mortos no momento da primeira avaliação (Tabela 6). Passados 70 dias, durante a segunda avaliação (Tabela 7) observou-se 2 adultos vivos e um em fase final de pupação, ainda no interior de um pedaço de macarrão que se encontrava presente na amostra. Isso caracteriza que um lote de macarrão contendo insetos foi transportado pelo referido caminhão, e resíduos deste material permaneceram na carroceria, gerando potencial de contaminação de outros materiais que ali viessem a ser transportados. A presença de Sitophilus $s p$. em macarrão pode ser explicada através do 
entendimento do processo de fabricação desse produto. Como a farinha, principal matéria-prima, normalmente possui ovos de carunchos, gorgulhos e traças, os quais não são eliminados durante a moagem do trigo (Menschoy, 1982), durante a fabricação do macarrão, em momento algum existem processos físicos como calor ou mecânico (batimento ou centrifugação) que venham a garantir a efetiva quebra ou desnaturação das proteínas dos ovos. Nem mesmo a passagem do macarrão pelos secadores onde o binômio temperatura e tempo de exposição deveria eliminar tais ocorrências pode ser considerado como um ponto de controle comprovado, principalmente porque se desconhece a temperatura real no interior da massa do macarrão Dessa forma, associado ao fato de que os estoques de farinha normalmente não permitem que fumigações com fosfeto de alumínio ou magnésio sejam realizadas, face ao tempo de exposição, que deve ser de 120 horas e por isso considerado muito alto para manter o material em desuso, e a baixa eficiência deste tratamento contra ovos de insetos, a possibilidade de emergência, principalmente de espécimes de Sitophilus $s p$. que são pragas primárias em trigo e necessitam de materiais compactos para o desenvolvimento de suas fases larvais e pupais é bastante grande. Nesse caso, o fato do macarrão estar na carroceria do caminhão propiciou a presença de insetos vivos na amostra após 70 dias, exemplificando bem o potencial de determinados produtos alimentícios em gerar infestações cruzadas entre estabelecimentos ou produtos, utilizando veículos de transporte como um de seus agentes.

Odores de materiais que estejam sendo transportados, tais como derivados de cacau, frutas etc, ou mesmo açúcares diluídos presentes ao redor ou mesmo no interior das carrocerias, podem ser um dos motivos da 
atração de abelhas, vespas e moscas para as proximidades das docas e, consequentemente das carrocerias. Indústrias que utilizam açúcar, muitas vezes geram resíduos (cristais) que caem no piso das docas durante o carregamento e principalmente no descarregamento. Como em empresas alimentícias as rotinas de limpezas externas são normalmente líquidas e freqüentes, porém muitas vezes sem o cuidado necessário, acabam utilizando jatos de água sem a devida preocupação com a correta eliminação dos resíduos. Ao diluir cristais de açúcar presentes no piso, os transformam da forma sólida, muito pouco disponível para insetos com aparelho bucal sugador, para açúcar diluído, prontamente disponível para abelhas, aumentando assim seu poder de a tração.

Ralos localizados nas proximidades das docas também podem originar a presença de Periplaneta americana (Blattodea : Blattidae) e de certos dípteros em caminhões. Ao sair do interior destes ambientes, os insetos podem atingir o veículo através de vôo ou pelo auxílio de materiais ali depositados. Assim como os ralos, todo o ambiente que circunda a área de docas deve ser permanentemente monitorado e mantido sobre rigorosas práticas de limpeza e conservação. Recipientes de coleta de lixo que permanecem sem tampa ou demasiadamente cheios, "containers" de coleta de resíduo mal lavados ou com freqüência de retirada muito espaçada, jardins com árvores frutíferas, com muitas flores ou que recebam adubação orgânica regularmente podem caracterizar pontos de atração e conseqüente risco à infestação de carrocerias.

Cupins, como do gênero Cryptotermes (Isoptera : Kalotermitidae) (Tabela 5), podem facilmente entrar voando em carrocerias quando da época da revoada, e principalmente em "pallets" pré-atacados, podendo 
colonizar as travessas de madeira ou placas de compensado existentes no interior dos caminhões baú (Figura 11) ou as próprias carrocerias de caminhões lonados ( Figura 12), e delas perfurar caixas de papelão e entrar em contato com produtos terminados. Os danos referentes ao ataque de cupins aos "pallets" são considerados críticos para as indústrias, não apenas pelo risco de contaminação do produto final, mas também pelo fato de, ao atacarem as travessas de madeira que compõem a estrutura do "pallet", os insetos reduzem sua resistência, permitindo que cargas que estejam empilhadas possam sofrer avarias, quedas e mesmo gerar risco à segurança de operários. Nesse sentido, o uso de caminhões baú, cuja carroceria apresenta estrutura rígida e definida, é considerada como item de segurança para cargas que possam ser transportadas empilhadas em mais de um "pallet", principalmente porque minimizam os riscos de perda da estrutura das pilhas caso haja a ruptura de uma travessa de sustentação durante o período de transporte.

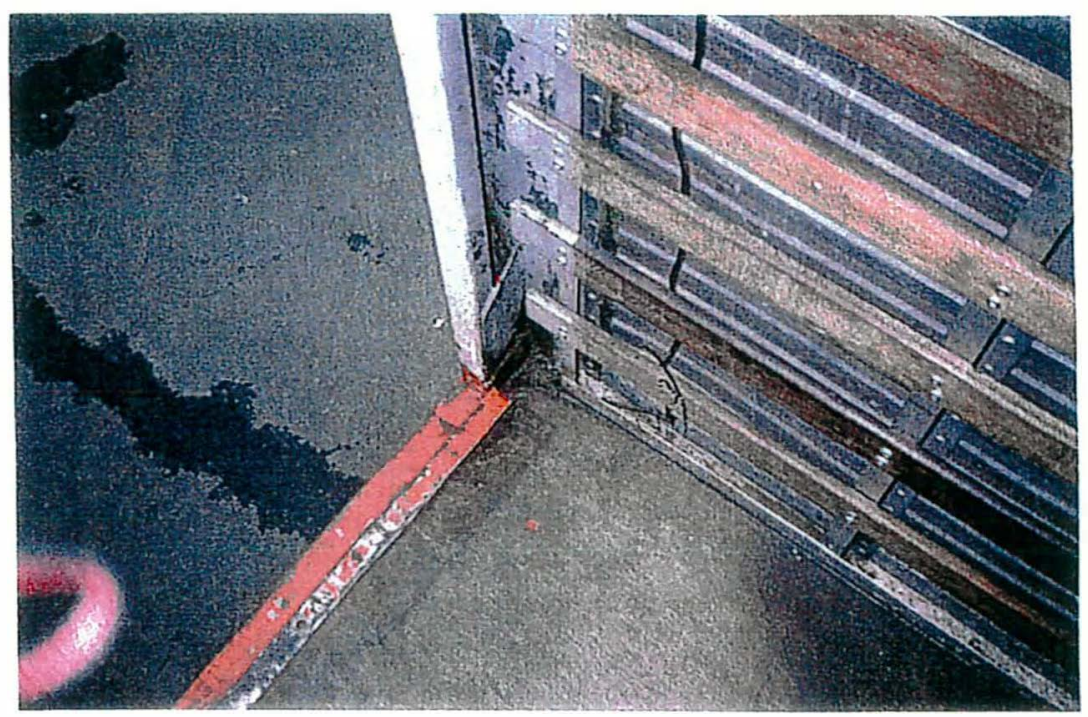

Figura 11: Travessas e compensados de madeira que podem abrigar colônias de cupins do gênero Cryptotermes (Isoptera : Kalotermitidae) no interior de carrocerias de caminhões. 


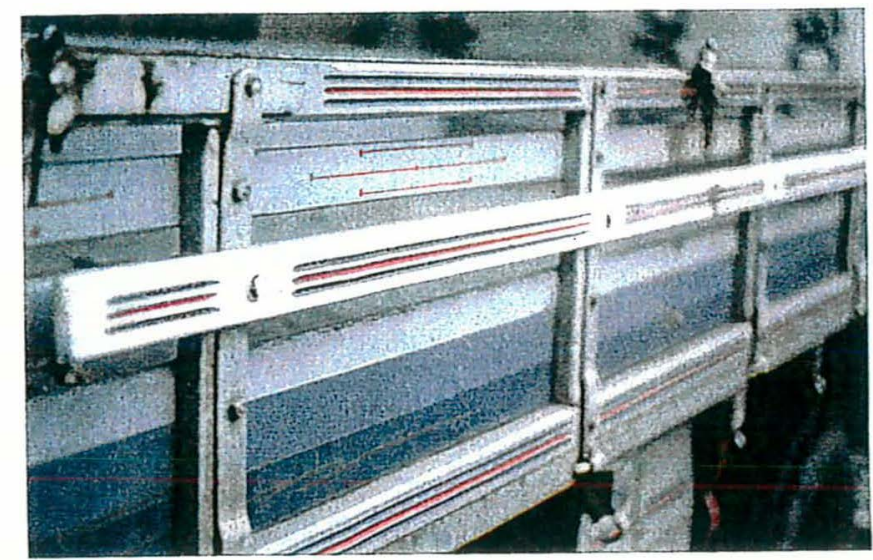

Figura 12: $\quad$ Carroceria de caminhões lonados que podem abrigar colônias de cupins do gênero Cryptotermes (Isoptera : Kalotermitidae).

Psocópteros do gênero Liposcelis (Psocoptera : Liposcelidae) (Turner \& Maude-Roxby, 1988), freqüentes em caminhões baú (Tabela 5), e ácaros, acessórios em qualquer tipo de carroceria (Tabelas 2, 5 e 8), por serem ápteros, somente podem ser introduzidos em carrocerias de caminhões através de algum meio como mercadorias contaminadas, "pallets" ou caixas de papelão, e no caso dos ácaros através também de hospedeiros foréticos (Flechtmann, 1986). No interior das carrocerias, estes talvez sejam os artrópodos que apresentam-se mais adaptados à colonização das mesmas face às condições que requerem para seu desenvolvimento. Necessitam de umidade relativa acima de $70 \%$, vivem perfeitamente em meios com temperatura média acima de $30{ }^{\circ} \mathrm{C}$ (Rees \& Walker, 1990), 
consomem materiais contidos em poeira, como esporos de fungos, restos vegetais e de insetos, substratos estes encontrados quase que na totalidade das carrocerias (Figura 13). Por serem de difícil visualização, ainda hoje são pouco conhecidos na indústria de alimentos e, principalmente do consumidor, onde passam despercebidos em muitos processos analíticos, reduzindo assim sua importância como agente de depreciação da qualidade de alimentos. Contudo, pelos resultados encontrados (Tabela 2), comportaram-se como os artrópodos de maior potencial para contaminar materiais e originar infestações cruzadas entre indústrias e pontos de venda.

A constante presença de fragmentos de insetos em caminhões lonados e baú ( Figura 14) vem confirmar a suposição inicial do levantamento que seria grande a presença e até a atividade de insetos no interior das carrocerias de caminhões, cuja perfeita identificação pode ter sido prejudicada pela metodologia amostral utilizada, ou ainda, que tal acúmulo é fruto de anos de utilização dos veículos sem a correta higienização.

Pelos resultados discutidos, verifica-se que há plenas condições para artrópodos penetrarem acidentalmente em carrocerias de caminhões e até colonizá-las. Contudo, o risco efetivo para produtos alimentícios transportados em caminhões seria sua contaminação por insetos ou aracnídeos, ou mesmo estes virem a infestar matérias-primas, materiais de embalagem ou "pallets" e, posteriormente, acarretarem contaminação de maiores proporções no processo produtivo. 


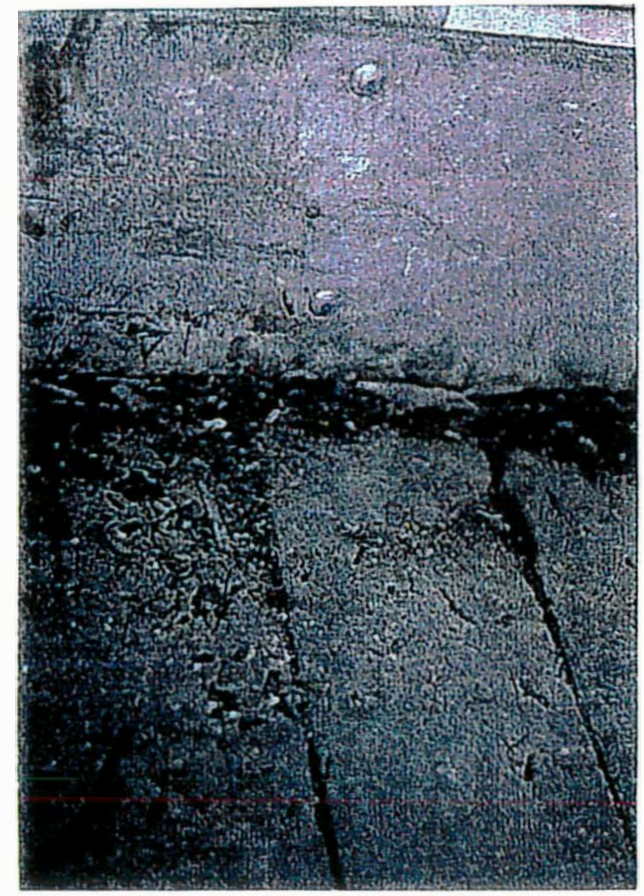

Figura 13: Detalhe da presença de poeira e resíduos oriundos de antigos transportes nas carrocerias de caminhões baú.

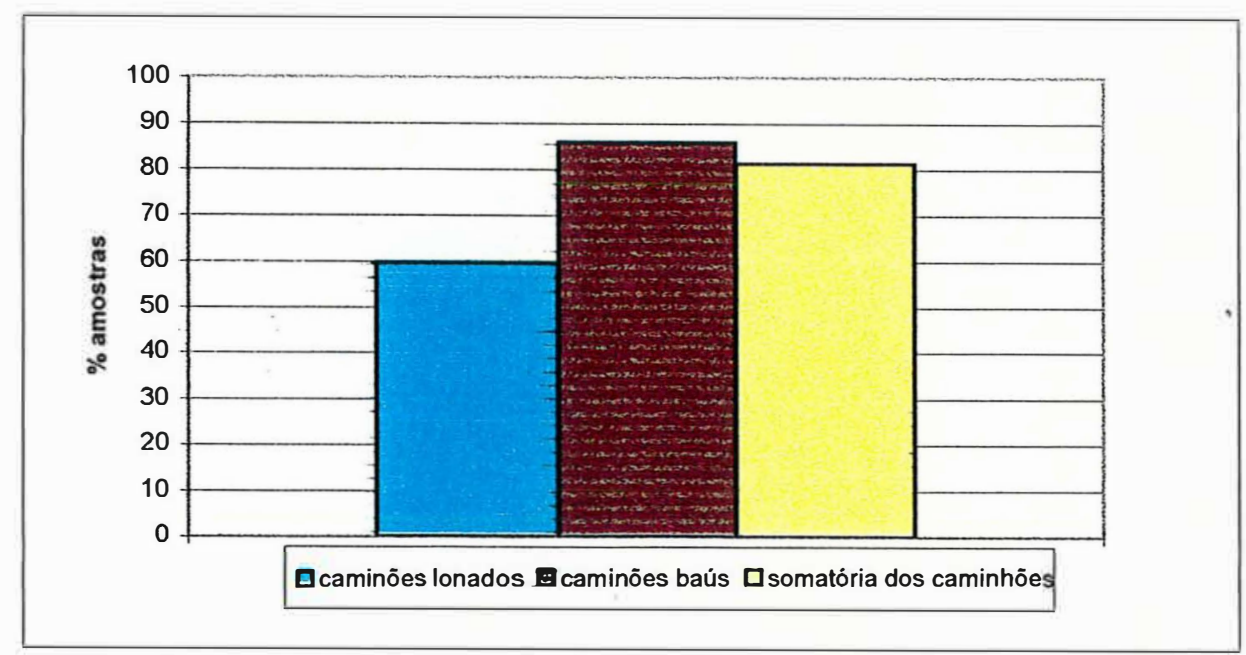

Figura 14: $\quad$ Porcentagem das amostras de caminhões lonados, baú e caminhões em geral, contendo fragmentos de insetos. 
$\mathrm{O}$ risco de determinadas embalagens de produtos finais, como filmes plásticos, laminados, sacarias de papel etc serem perfuradas por insetos foi motivo de revisão realizada por Bauer (1985). O autor verificou que formas imaturas de : Ephestia spp (Lepidoptera : Pyralidae), Lasioderma serricorne (Coleoptera : Anobiidae), Oryzaephilus spp. (Coleoptera : Silvanidae), Plodia interpunctella (Lepidoptera : Pyralidae), Sitotroga cereallella (Lepidoptera : Gelechiidae), Tribolium spp. (Coleoptera : Tenebrionidae), e adultos de Sitophilus spp. (Coleoptera : Curculionidae) etc, possuem aparelho bucal capaz de perfurar a grande maioria das embalagens comumente empregadas na indústria de alimentos. $\mathrm{O}$ autor destacou ainda que, mesmo sem a necessidade de perfuração, muitas delas apresentam-se suscetíveis à penetração por parte de insetos e ácaros em defeitos de selagem lateral e em possíveis dobras existentes nas suas extremidades, onde a vedação não ocorre perfeitamente, possibilitando acesso ao seu interior. Uma vez vencida a barreira da embalagem, os produtos podem ser atacados, e os próprios insetos ou seus vestígios, como fezes, exúvias ou teias, podem caracterizar dano. Deve-se destacar também que uma embalagem de produto alimentício que venha a ser perfurada por insetos, mesmo que estes não a colonizem, permitirá o contato do meio externo com o interior do produto, prejudicando assim suas características organolépticas e físicas, além de aumentar o risco de penetração de microrganismos e conseqüente contaminação. Zdarkova et al (1983) revelou que produtos alimentícios atacados por insetos podem naturalmente também conter ácaros que foram comensalmente transportados pelos primeiros. Dentro do meio, os ácaros tendem a realizar constantes migrações entre a superficie e o fundo, facilitando disseminação 
microbiológica e gerando pequenos aumentos de temperatura, isso mais facilmente observado em massas de grãos armazenados.

\subsection{Comparação entre carrocerias baú e lonadas}

Analisando-se separadamente carrocerias baú e lonadas, verificouse que as primeiras apresentam maior potencial para abrigo de artrópodos acidentais e desenvolvimento populacional de Blattella germanica (Blattodea : Blattellidae), psocópteros e ácaros, vindo de encontro com o proposto por Hederson \& Meinster (1977), que apontaram veículos com carrocerias fechadas como mais adequados a manter populações de insetos em seus interiores. Enquanto caminhões baú apresentaram uma relação de 1,27 insetos coletados por amostra, em lonados a relação foi de 0,40 . Para entender melhor esta diferença, deve-se destacar a ausência de psocópteros nas primeiras análises de caminhões lonados (Tabela 9), somente sendo observados 2 indivíduos na avaliação após 70 dias de quarentena (Tabela 10) (Figura 15). Tal fato deve ser considerado porque psocópteros foram os insetos mais coletados em caminhões baú (Tabela 5) e isso fez com que a relação numérica entre as carrocerias baú e lonadas apresentasse valores tão espaçados. Contudo pode-se interpretar que carrocerias lonadas comportam-se como ambientes menos favoráveis para a colonização por insetos quando comparada às carrocerias baú, visto que os únicos insetos vivos encontrados foram os dois psocópteros durante a segunda avaliação da amostra 13 (Tabela 1). Smith \& Whitman (1992) destacaram que insetos da Ordem Psocoptera não suportam ambientes que 


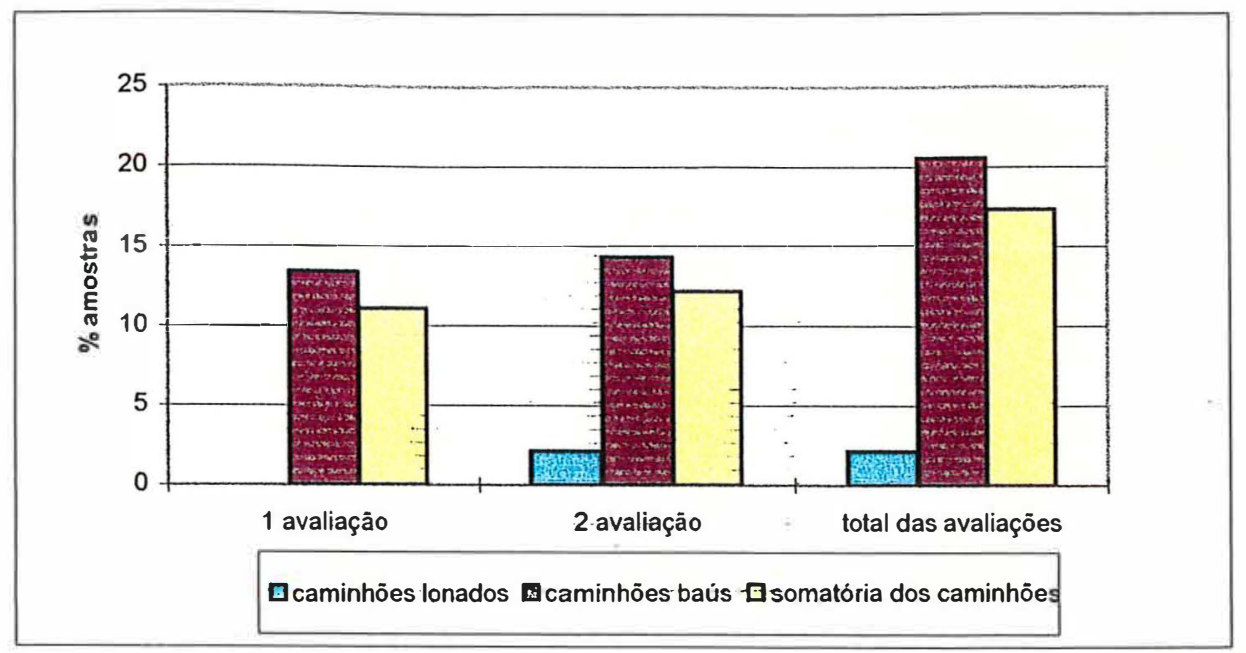

Figura 15: $\quad$ Porcentagem de amostras de caminhões baú, lonados e de caminhões em geral, contendo insetos da Ordem Psocoptera.

recebem ação direta da luz solar, fato este que, em caminhões lonados, pode responder pela sua ausência durante a primeira análise e sua restrita captura após a quarentena. A rotina de carregamento e descarregamento deste tipo de caminhões normalmente ocorre em ambientes abertos, fazendo com que sua carroceria permaneça exposta à ação da luz solar, chuva, vento etc. Já carrocerias baú comportam-se como ambientes contendo microclimas próprios, protegidas de luz e com maior potencial para manutenção de umidade relativa mais elevada, além de possuírem maior número de frestas, pontos estes que facilitam o acúmulo de pó e conseqüente desenvolvimento de fungos, substrato alimentar fundamental na dieta de psocópteros (Pacheco \& de Paula, 1995). 
Como os fragmentos de insetos foram constantes em carrocerias lonadas (Tabela 8), entende-se que nelas há entrada de insetos, face à sua total vulnerabilidade quando em carregamento ou descarregamento, ou mesmo durante o transporte, visto que muitas vezes suas lonas estão rasgadas. Contudo, tais veículos apresentam menor potencial para desenvolvimento populacional ou mesmo sobrevivência das espécies de ocorrência acidental, quando comparados a carrocerias baú, exceção feita para ácaros, que se comportaram de forma acessória em ambos os sistemas (Figura 16). Como ácaros e psocópteros normalmente habitam ambientes semelhantes, acredita-se que o fato de algumas espécies destes aracnídeos não apresentarem suscetibilidade tão elevada à luz solar, somando-se a isto o fato destes poderem ser mais facilmente conduzidos na forma de deutoninfas ao interior das carrocerias através de hospedeiros foréticos, como outros insetos, acabam aumentando em muito seu potencial de penetração e permanência nesse tipo de carroceria, quando comparado aos psocópteros.

As Ordens de insetos que ocorreram acidentalmente em caminhões lonados e baú (Tabelas 5 e 8 ) foram analisadas relativamente ao número de amostras de cada tipo de veículo (Figuras 17 e 18), sendo constatados valores notadamente superiores para Blattodea, Hymenoptera e Psocoptera em carrocerias baú, quando comparadas às lonadas. Isso caracteriza que o possível erro amostral, oriundo da metodologia empregada, pode ser reduzido na análise dos resultados. Se efetivamente a aspiração viesse a quebrar os insetos em sua grande maioria, não seria possível a diferenciação quantitativa e qualitativa entre Ordens nos dois tipos de carrocerias, 


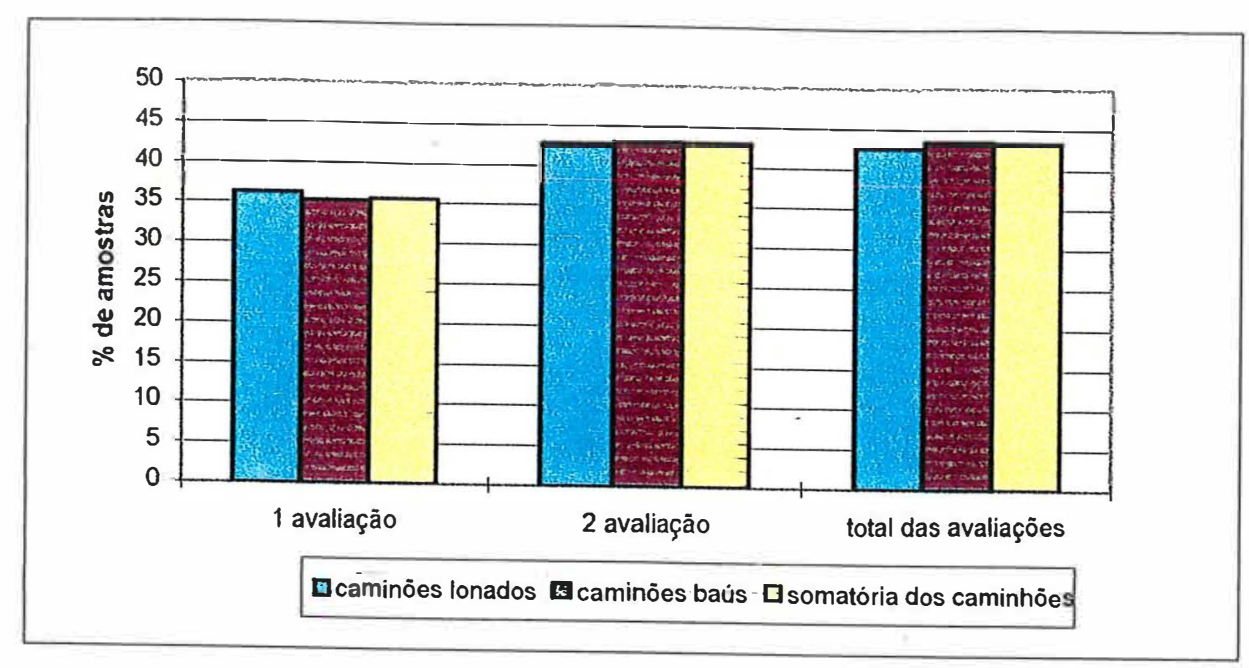

Figura 16: Porcentagem de amostras de caminhões baú, lonados e de caminhões èm geral contendo ácaros.

havendo apenas uma homogeneidade de resultados no tocante a fragmentos de insetos. Essa evidência é maior para himenópteros e baratas, visto que psocópteros não são tão suscetíveis à quebra através de amostragens por aspiração, cujo procedimento é citado por Borror \& Delong (1988) como indicado para captura destes insetos.

Em caminhões baú, psocópteros e himenópteros foram freqüentes (Tabela 5 e Figura 18). Em lonados, as Ordens Hymenoptera, Coleoptera e Diptera comportaram-se de forma freqüente (Tabela 8 e Figura 17). Ainda em lonados, destaque para Tribolium castaneum (Coleoptera : Tenebrionidae) que também comportou-se como espécie freqüente. Este resultado para $T$. castaneum pode ser explicado pelo fato de normalmente farinhas serem transportadas em caminhões desse tipo e, este tenebrionídeo 
ser praga primária em farinhas, sendo constantemente encontrado em amostras deste material oriundo de moinhos. Embora não se tenha amostrado veículos que estavam transportando farinhas, a presença de carunchos pode comprovar o potencial de contaminação das carrocerias quando utilizadas para o transporte de inúmeros materiais, sem o devido procedimento de limpeza entre carregamentos.

Analisando-se os resultados da primeira avaliação (Tabelas 3, 6, 9) com os da segunda (Tabelas 4, 7, 10), realizada após 70 dias da coleta, pode-se verificar que os ácaros (Figura 16) foram encontrados com ligeira superioridade durante a segunda análise. Esse resultado, mesmo interpretando que os ácaros não foram retirados da amostra na análise inicial, juntamente com a presença exclusiva de psocópteros na segunda avaliação de caminhões lonados (Tabela 10 e Figuras 15 e 18), e as de Sitophilus sp. (Coleoptera : Curculionidae) e Gnathocerus sp. (Coleoptera : Tenebrionidae) na segunda avaliação de caminhões baú (Tabela 6), confirma a condição de desenvolvimento de gerações de determinados artrópodos no interior do substrato existente nas carrocerias.

Nesse caso, os insetos encontrados na segunda avaliação podem ser considerados pragas primárias em meios de transporte, segundo a classificação proposta por Schoenherr \& Rutledge (1991) por poderem se desenvolver no interior de carrocerias e atacar produtos transportados. Pela mesma classificação, somariam-se a eles os seguintes insetos amostrados durante a primeira análise (Tabela 3): Tribolium sp., T. castaneum, $O$. surinamensis, B. germanica, L. serricorne e Cryptotermes sp.; todos estes por serem capazes de consumir produtos transportados. 


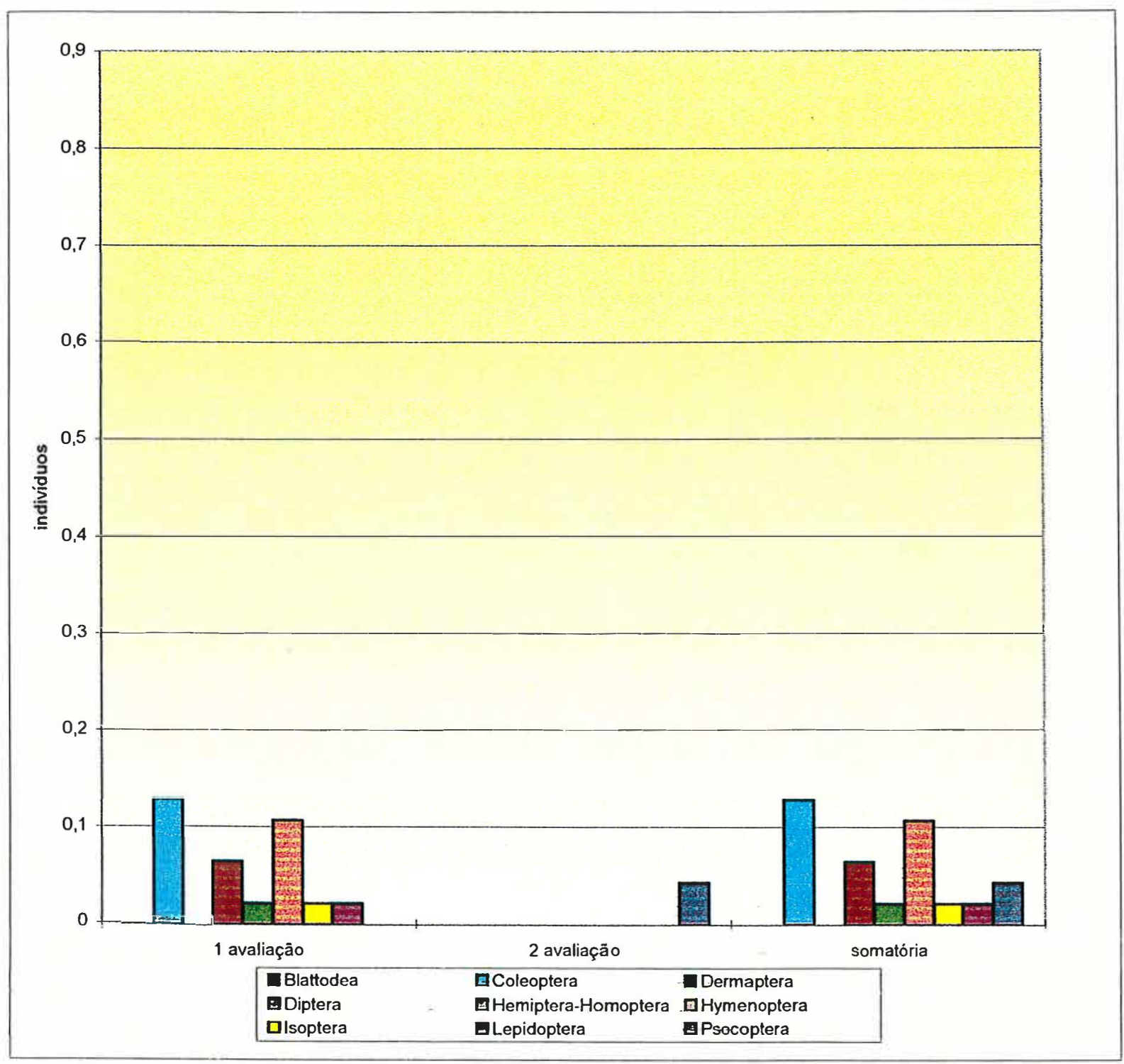

Figura 17: Relação entre o total de amostras e o número de insetos por Ordens amostrados em caminhões lonados. 


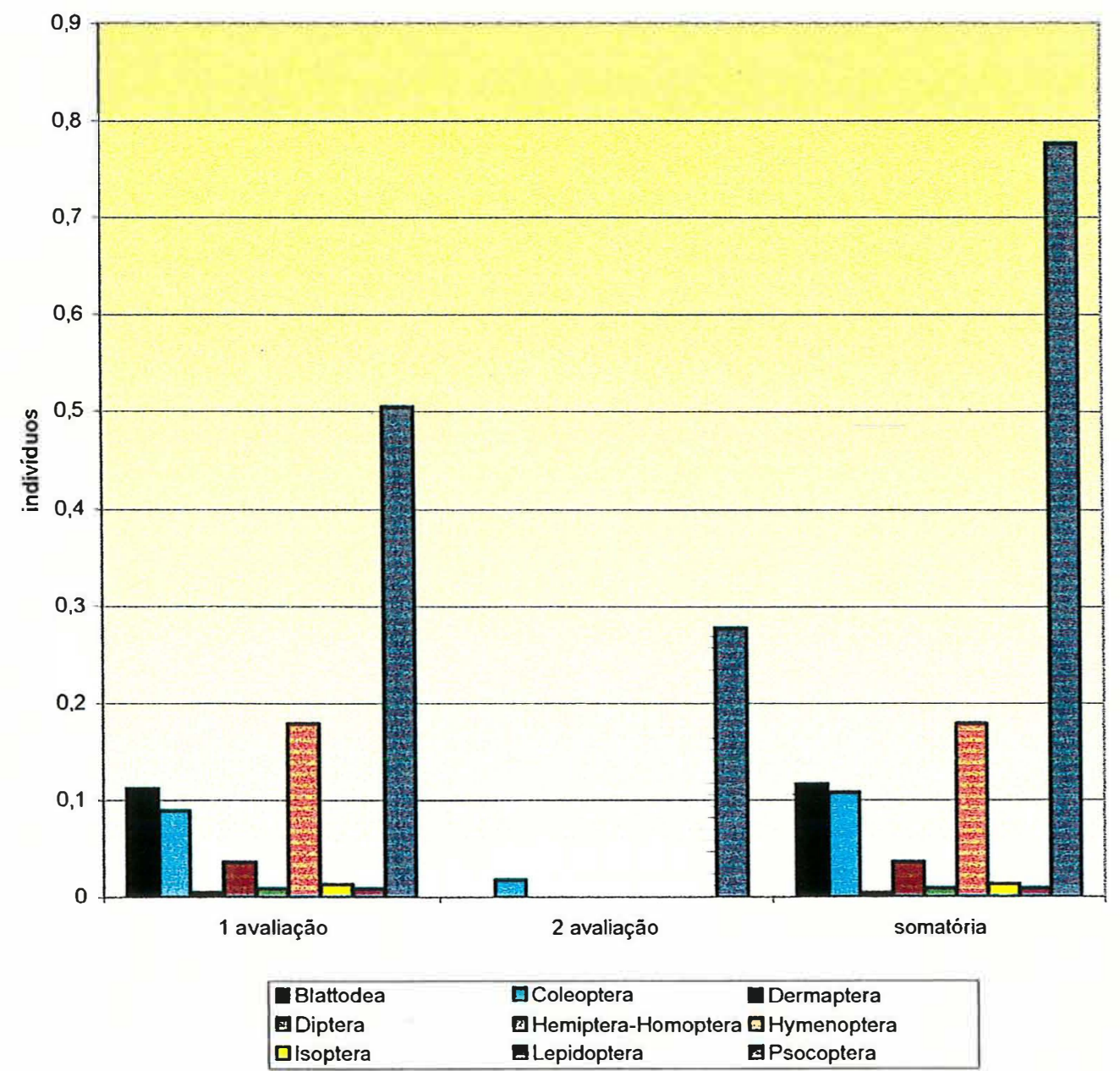

Figura 18: Relação entre o total de amostras e o número de insetos por Ordens amostrados em caminhões baú. 
Periplaneta americana (Blattodea : Blattidae) e determinados muscídeos (Diptera) poderiam oscilar entre pragas primárias ou secundárias em meios de transporte, nessa última condição por poderem caracterizar condição higiênica ou estado de conservação do material transportado. Os demais insetos coletados seriam consideradas pragas acidentais também pela classificação de Schoenherr \& Rutledge (1991).

\subsection{Possibilidades de controle}

Práticas de controle que venham a evitar ocorrências de insetos em carrocerias de caminhões, como as detectadas neste levantamento, recaem basicamente em medidas preventivas, onde a limpeza dos veículos representaria o alicerce de qualquer programa, vindo de encontro com o proposto por Hederson \& Meinster (1977).

Evitar que qualquer carregamento seja realizado sem completo processo de higienização reduziria a existência de poeira e resíduos de produtos anteriormente transportados, eliminando assim esporos de fungos, insetos mortos, e restos das referidas mercadorias, as quais atuam como agentes de proliferação de ácaros e insetos de produtos armazenados.

Qualquer procedimento de limpeza em carrocerias, antes de ser realizado, deve ser estudado previamente, analisando-se a melhor metodologia a ser empregada dentro do tempo disponível para a reutilização do veículo.

Limpezas líquidas, usando-se água quente e detergente para melhor eliminação de resíduos e incrustações, seria uma das alternativas, 
inclusive citada por Flechtmann (1986) como método de controle de ácaros em ambientes. Contudo essa metodologia somente poderia ser empregada se houvesse tempo suficiente para correta secagem da carroceria, caso contrário a umidade poderia acarretar sérios prejuízos, como a atração de insetos, o aumento da umidade relativa do meio, e conseqüente formação de microclima favorável à proliferação de artrópodos e desenvolvimento de microrganismos.

O uso de vassouras ou de ar comprimido são métodos considerados válidos, mas se não utilizados com cuidado podem acabar gerando dispersão ou transferência de focos de artrópodos e resíduos no interior de uma carroceria. $\mathrm{O}$ ar comprimido é um método de difícil controle de seu raio de ação, e as vassouras, se não limpas em curtos intervalos de tempo, podem inclusive servir de fonte de infestação cruzada entre carrocerias.

A aspiração, desde que realizada de forma industrial, com equipamentos potentes e com grande capacidade de armazenamento seria uma das formas mais adequadas para uma correta limpeza. Bastaria para isso a utilização de filtros descartáveis ou adoção de rígidas rotinas de limpeza dos equipamentos, pelo fato dos aspiradores também poderem atuar como agentes de infestação cruzada entre ambientes.

Independente do método de limpeza, este deve ser ajustado à realidade de cada fábrica. Mesmo não sendo totalmente eficaz, mas desde que seja freqüente, pode ser considerado como importante agente na redução do potencial de desenvolvimento de contaminações por artrópodos 
em produtos transportados em caminhões, ou destes para o interior de processos produtivos ou armazéns fabris.

Limpar "pallets", verificar a possibilidade da redução do fluxo destes entre empresas e caminhões; evitar carregamento e descarregamento de carrocerias em docas externas à noite e, caso estas operações sejam necessárias, utilizar iluminação à base de vapor de sódio; eliminar frestas em carrocerias baú, assim como manter jardins, ralos e recipientes de coleta de lixo que estejam próximos de docas em perfeitas condições de manutenção, seriam medidas interessantes para a redução do potencial de acesso de insetos e aracnídeos ao interior de veículos de transporte.

Aplicações rotineiras de inseticidas em carrocerias não seria prática recomendada. Inicialmente porque se pode observar que a grande maioria dos caminhões apresenta considerável quantidade de poeira em suas superfícies. Aplicação de inseticidas sobre pó representaria grande perda de sua atividade, seja por absorção das partículas líquidas, por ação microbiana, ou por não atingir indivíduos que estivessem localizados abaixo da camada de poeira atingida (Mattheus. 1982). Tratamentos realizados após procedimentos de limpeza poderiam ser eficazes; contudo, caso novas higienizações não sejam realizadas, a camada de pó depositada sobre o filme residual do inseticida aplicado nas superficies seria suficiente para minimizar sua ação de controle.

O uso de inseticidas poderia ser justificado no caso do conhecimento da existência de focos de determinados insetos, como por exemplo B. germanica, cuja prática de limpeza aplicável para certos veículos não seria suficientemente capaz de eliminá-los. Nesse caso, o 
tratamento focal com inseticidas não residuais seria uma alternativa interessante (Halliday et al. 1987). Bastante cuidado deve ser dispensado quando da tomada de decisão por um tratamento químico no interior de uma carroceria de caminhão. Às vezes, procedimentos dessa natureza podem causar o aumento da população de ácaros, visto que ovos e deutoninfas dificilmente são controlados através de inseticidas, propiciando ainda a morte de predadores naturais e aumento do volume de matéria-orgânica com os cadáveres dos insetos que por ventura não sejam removidos por processos de limpeza; além disso, muitas vezes, aumentam a umidade do ambiente, proporcionando melhores condições para o desenvolvimento de fungos (Flechtmann, 1986), sem contar o risco de eventual residual químico excessivo presente nas carrocerias, e o uso de moléculas com potencial de corrosão de superfícies metálicas, o que reduziria o tempo útil de carrocerias baú.

As formas de aplicação de inseticida, quando de sua real necessidade, preferencialmente seriam pulverização em frestas e fendas, ultra-baixo volume ou termonebulização, mas suas adequações às melhores moléculas e dosagens necessitariam de estudos específicos, visto não haver recomendação para isso por parte dos fabricantes. Nesse caso, somente seria descartada a possibilidade de utilização de fumigantes no interior das carrocerias, inicialmente pela dificuldade de sua total vedação, além dos produtos comerciais com tal formulação disponíveis no mercado brasileiro não apresentarem registro junto ao Ministério da Saúde para uso em áreas urbanas, ou mesmo para tratamentos de estruturas como prédios, veículos etc. 


\section{CONCLUSÕES}

- A aspiração deve ser considerada como metodologia prática amostral da presença de artrópodos em carrocerias de caminhões quando do carregamento ou descarregamento de produtos em indústrias de alimento .

- Insetos e aracnídeos comportam-se como populações acessórias em caminhões.

- Psocópteros são os insetos mais adaptados a colonizar carrocerias de caminhões baú; já ácaros comportam-se semalhantemente tanto em carrocerias lonadas como baú.

- A limpeza adequada a rotina, tempo de reutilização e ao tipo de carga transportada é a melhor alternativa de remoção de insetos.e aracnídeos e prevenção de suas colonizações no interior de carrocerias de carninhões. 


\section{BIBLIOGRAFIA CONSULTADA}

ARMITAGE, D. M.; COGAN, P. M.; WILKIN, D. R. Integrated Pest Management in Stored Grain: Combining Surface Insecticide Treatment with Aeration. Journal of Stored Research, v.30, n.4, p. 303-319, 1994.

BAUER, F. Insect management for food storage and processing. $2^{\text {nd }}$ ed. Minneapolis: American Association of Cereal Chemists, 1985. $384 p$.

BENETT, G. H.; OWENS, J. M.; CORRIGAN, R. M. Truman's scientific guide of Pest Control Operations. $4^{\text {th }}$ ed. Duluth: Advanstar Communications, 1988. 485p.

BORROR, D. J. \& DeLONG, D.M. Introdução ao Estudo dos Insetos. $2^{a}$ ed. São Paulo: Editora Edgard Blümer. Ltda, 1988. 653p.

BRITTON, E.B. Coleoptera. In: CSIRO. The Division of Entomology.The Insects of Australia : Textbook for Students and Research Workers. Camberra: Melboune University Press, 1973. p.495-621.

BURKHOLDER, W. E. Stored product insect behavior and pheromone studies: keys to successful monitoring and trapping. In: $3^{\text {rd }}$ Int. 
Working Conf. Stored Prod. Ent., Manhattan, 1984. Proceeding. Manhattan: 1984. p:20-33.

COLLESS, D.H. \& McALPINE, D.K. Diptera. In: CSIRO. The Division of Entomology. The Insects of Australia : Textbook for Students and Research Workers. Camberra: Melboune University Press, 1973. p.656-740.

COOLEY, D.R. Food and the environment: IPM meets the $21^{\text {st }}$ century. American Phytopatholoical Society , 77, 3, p 296-299, 1993.

COMMON, T.F.B. Lepidoptera. In: CSIRO. The Division of Entomology.The Insects of Australia : Textbook for Students and Research Workers. Camberra: Melboune University Press, 1973. p.765-866

CORNWELL, P.B. The Cockroach London: Associated Business Programmes, 1968. v1. , 391p.

DOLE, P.S. \& MADDISON, P.A. Transport Services as an Aid to Insect Dispersal in the South Pacific. In: Commerce and the spread of Pests and Disease Vectors. New York: Praeger Publish, 1984 . 225-254p.

DAVIS, R. Introduction to Food-Pest Ecology and Management. In : GORHAM, J.R. Ecology and Management of Food -Industry Pests. Arlington: AOAC (Association of Official Analytical Chemists), 1991. p 3-4.

FLECHTMANN, C.H.W. Ácaros em Produtos Armazenados e na Poeira Domiciliar. Piracicaba : FEALQ, 1986. 97p.

FRISHMAN, A. Inspections \& Identification. In: $61^{\text {th }}$ Annual Convention of National Pest Control Association, Honolulu, 1994. Proceedings. Dunn Loring: NPCA, 1994. p 81-88p. 
GALLO, D.; NAKANO, O.; SILVEIRA NETO, S. et al. Manual de Entomologia Agrícola. $2^{\text {a }}$ ed. São Paulo: Editora Ceres, 1988. $644 \mathrm{p}$.

GORDON, D.G. The Compleat Cockroach. Berkeley: Ten Speed Press, 1996. $177 \mathrm{p}$.

HALLIDAY, W.R.; MORGAN, N.O.; KIRKPATRIK, R.L. Evaluation of insecticides to control of stored-product pests in transport vehicles. Journal of Entomological Science, 22, 3, p. 225-236, 1987.

HEDERSON, L.S. \& MEINSTER, H.E. Guidelines for Pest Control in Railcars for Food Transportation. Program Aid 1178. Agricultural Research Service, U.S. Department of Agriculture, Washington, DC. 1977. 28p.

HEDGES, S.A. Field Guide for the Management of Structure Infesting Flies. Cleveland: Franzak \& Foster Co., 1993. 151p.

HEDGES, S. A. \& LACEY, M.S. Field Guide for the Management of Urban Spiders. Cleveland: Franzak \& Foster Co., 1995. 220p.

HICHIN, N.E. Household Insect Pests. London: Associated Business Programmes London, 1974. 176p.

HILL, D.S. Pests of Stored Products and their Control. Boston: CRC Press, 1990.272p.

HOLMAN, R.L. Food Industry Self-Inspection. In: GORHAM, J.R. Ecology and Management of Food -Industry Pests. Arlington: 
AOAC (Association of Official Analytical Chemists), 1991. p. 519528.

JAY, E.; DAVIS, R.; ZEHNER, J. M. In Transit Fumigation of TruckShip Containers with Hydrogen Phosphide. USDA. Agricultural Research Service, Advances in Agricultural Technology. New Orleans: AAT-S, 1983. p. 1-11.

MACKERRAS, J. Blattodea. In: CSIRO. The Division of Entomology.The Insects of Australia : Iextbook for Students and Research Workers. Camberra: Melboune University Press, 1973. p.262-274.

MALLIS, A. Handbook of Pest Control. $7^{\text {th }}$ ed. Cleveland: Franzak \& Foster Co, 1990. 1152p.

MAtTheUS, G.A. Pesticide Application Methods. London: Longman, 1982. 336p.

MENSCHOY, A. B. Pragas do trigo no campo e no armazém. In: Trigo no Brasil. Campinas: Fundação Cargill, 1982. p. 353-377.

MUIRHEAD-THOMSON, R.C. Trap responses of Flying Insects. San Diego : Academic Press, 1991. p. 66-93.

NAKANO, O.; SILVEIRA NETO, S.; ZUCCHI, R. A . Entomologia Econômica. Piracicaba: Livroceres, 1981. p. 24.

PACHECO, I. A . \& de PAULA, D. C. Insetos de Grãos Armazenados Identificação e Biologia. Campinas : Fundação Cargill, 1995. 229p.

PEDIGO, L.P. \& BUNTIN, G.D. Handbook of sampling methods for arthropods in agriculture. Boca Raton : CRC Press, 1994. p. 73-98. 
REES, D. P. \& WALKER, A. J. The effect of temperature and relative humidity on population growth of three Liposcelis species (Psocoptera : Liposcelidae) infesting stored products in tropical countries. Bulletin of Entomological Research, 80, p. 353-8, 1990.

RIEK, T,F,B. Hymenoptera. In: CSIRO. The Division of Entomology.The Insects of Australia : Textbook for Students and Research Workers. Camberra: Melboune University Press, 1973. p.867-959.

ROBINSON, W.H. Urban Entomology. London: Chapman \& Hall, 1996, $430 \mathrm{p}$.

SCHOENHERR, W.H. \& RUTLEDGE, J.H. Prevention and Management the Pest Problems Associated with Transportation of Food. In: GORHAM, J.R. Ecology and Management of Food -Industry Pests. Arlington: AOAC (Association of Official Analytical Chemists), 1991. p. 351-357.

SERVICE, M.W. Medical Entomology. London: Chapman \& Hall, 1996. $278 \mathrm{p}$.

SILVEIRA NETO, S.; NAKANO, O.; BARBIN, D.; VILLA NOVA, N.A. Manual de Ecologia de Insetos. São Paulo: Agronômica Ceres, 1976. $419 p$.

SMITH, E.H. \& WHITMAN, R.C. National Pest Control Association Field Guide to Structural Pests. Dunn Loring: NPAC, 1992. 551p.

SMITHERS, C.N. Psocoptera. In: CSIRO. The Division of Entomology.The Insects of Australia : Textbook for Students and Research Workers. Camberra: Melboune University Press, 1973. p.367-375. 
STORER, T.I. \& USINGER, R.L. Zoologia Geral. $5^{\text {a }}$ ed. São Paulo: Editora Nacional, 1979. 755p.

TROLLER, J.A. Sanitation in Food Processing. New York: Academic Press, 1983. 456p.

TURNER, B.D. \& MAUDE-ROXBY, H. Starvation survival of the stored product pest Liposcelis bostrychaphilus Badonnel (Psocoptera : Liposcelidae). Journal of Stored Products Research, 24, 1, p.23-28, 1988.

ZDARKOVA, E.; VERNER, P. H.; NOVOSAD, J. Disperson and distribution of mites and beetles in stored grain. Journal of Stored Products Research, 19, 2, p.73-80, 1983.

WALKER, A. Arthropods of Humans and Domestic Animals. London : Chapman \& Hall, 1994. 213p. 
Tabela 1. Artrópodos e fragmentos de insetos $(F)$ encontrados nas amostras (A) realizadas em caminhões (C) lonados (L) e baús (B), na região metropolitana de São Paulo de outubro de 1996 a outubro de 1997. Valores observados entre parênteses representam o número de indivíduos. A letra $m$ indica que os indivíduos amostrados estavam mortos.

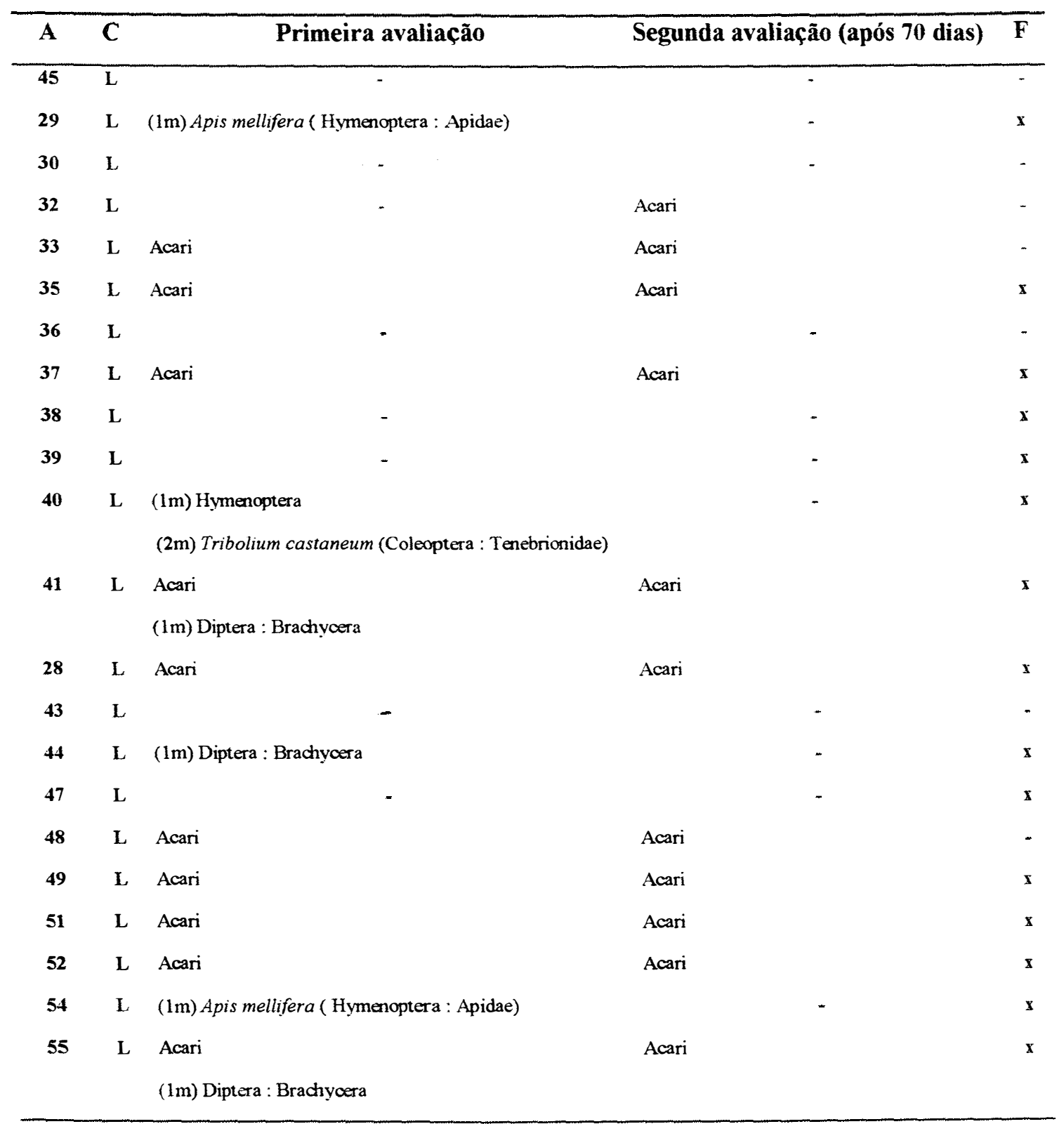




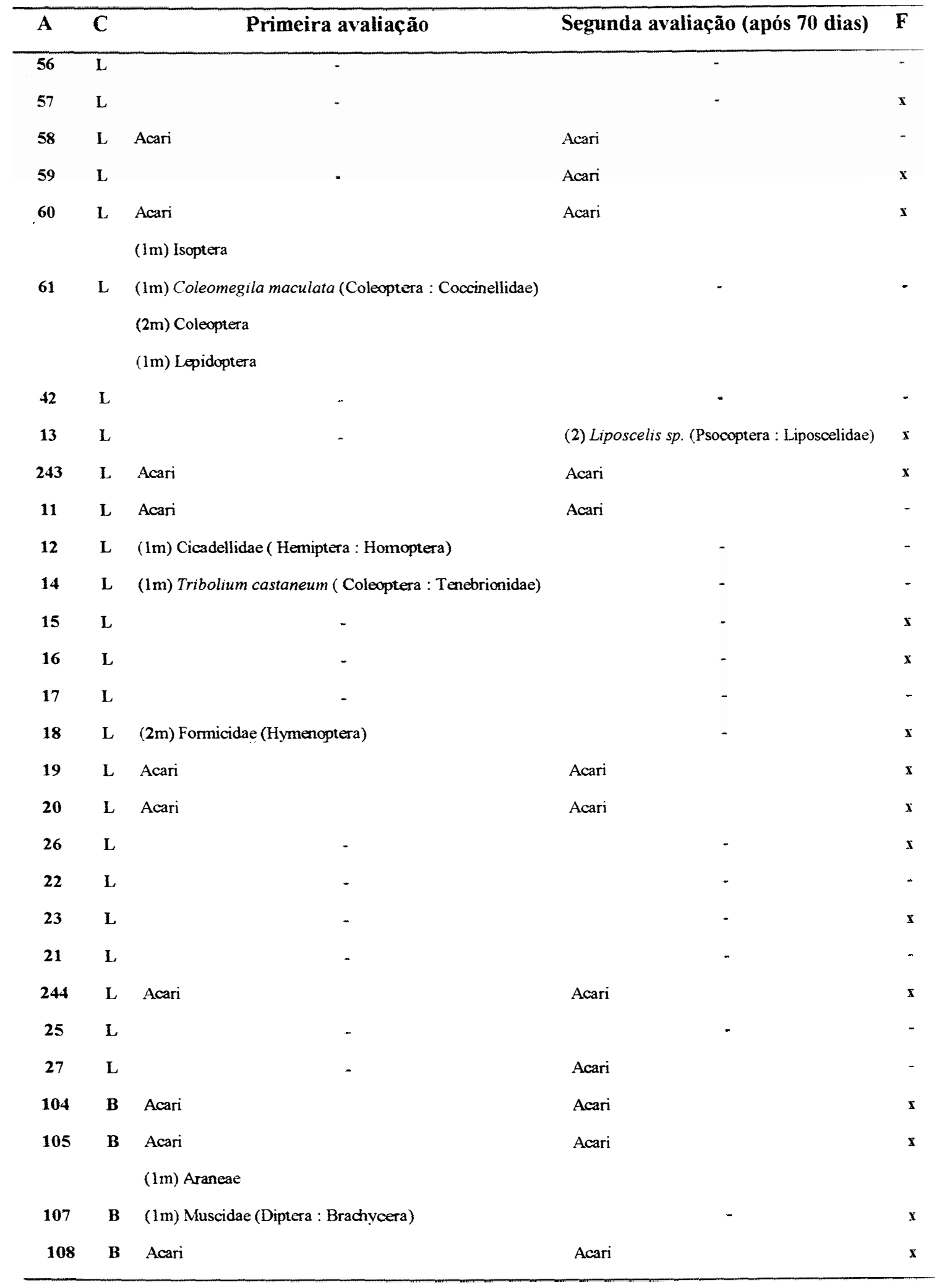




\begin{tabular}{|c|c|c|c|c|}
\hline $\mathbf{A}$ & C & Primeira avaliação & Segunda avaliação (após 70 dias) & $\mathbf{F}$ \\
\hline 99 & $\mathbf{B}$ & $\begin{array}{l}\text { (16m) Formicidae (Hymenoptera) } \\
\text { (3) Liposcelis sp. ( Psocoptera : Liposcelidae) }\end{array}$ & (1) Liposcelis sp. (Psocoptera : Liposcelidae) & $x$ \\
\hline 103 & $\mathbf{B}$ & $\begin{array}{l}\text { Acari } \\
(1 \mathrm{~m}) \text { Formicidae (Hymenoptera) }\end{array}$ & Acari & $\mathbf{x}$ \\
\hline 109 & B & $\begin{array}{l}\text { Acari } \\
\text { (1m) Formicidae }\end{array}$ & Acari & $x$ \\
\hline 110 & B & Acari & Acari & - \\
\hline 111 & B & Acari & Acari & $\mathbf{x}$ \\
\hline 106 & B & - & - & $\mathbf{x}$ \\
\hline 102 & $\mathbf{B}$ & $(1 \mathrm{~m})$ Coleoptera & - & $x$ \\
\hline 97 & B & 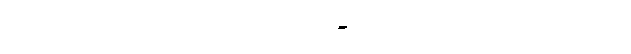 & - & $\mathbf{x}$ \\
\hline 100 & $\mathbf{B}$ & (1m) Apis mellifera (Hymenoptera : Apidae) & - & $\mathbf{x}$ \\
\hline 98 & $\mathbf{B}$ & - & - & $\mathbf{x}$ \\
\hline 112 & B & Acari & Acari & $\mathrm{x}$ \\
\hline 92 & B & Acari & Acari & $\mathbf{x}$ \\
\hline 131 & $\mathbf{B}$ & Acari & Acari & $\mathbf{x}$ \\
\hline 96 & B & $\begin{array}{l}\text { (1m) Blattella germanica (Blattodea: Blattellidae) } \\
\text { (lm) Formicidae (Hymenoptera) }\end{array}$ & - & $\mathbf{x}$ \\
\hline 95 & B & $\begin{array}{l}\text { (1m) Blattella germanica ( Blattodea : Blattellidae) } \\
\text { (1m) Formicidae (Hymenoptera) }\end{array}$ & $\begin{array}{l}\text { Acari } \\
\text { (3) Liposcelis sp. (Psocoptera: Liposcelidae) }\end{array}$ & $\mathbf{x}$ \\
\hline 93 & $\mathbf{B}$ & (17) Liposcelis sp. (Psocoptera : Liposcelidae) & - & $\mathbf{x}$ \\
\hline 94 & B & - & Acari & $\mathbf{x}$ \\
\hline 101 & B & Acari & Acari & $\mathbf{x}$ \\
\hline 127 & B & - & - & $\mathbf{x}$ \\
\hline 123 & $\mathbf{B}$ & $\begin{array}{l}\text { Acari } \\
\text { (1m) Formicidae (Hymenoptera) }\end{array}$ & Acari & $\mathbf{x}$ \\
\hline 122 & B & $\begin{array}{l}\text { Acari } \\
\text { (lm) Hymer optera }\end{array}$ & Acari & $\mathbf{x}$ \\
\hline 124 & $\mathbf{B}$ & - & Acari & $\mathbf{x}$ \\
\hline 67 & $\mathbf{B}$ & Aari & $\begin{array}{l}\text { Acari } \\
\text { (3) Liposcelis sp. (Psocoptera: Liposcelidae) }\end{array}$ & $\mathbf{x}$ \\
\hline 120 & B & - & Acari & $\mathbf{x}$ \\
\hline 91 & B & Acari & Acari & $\mathbf{x}$ \\
\hline 125 & B & - & 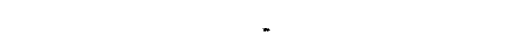 & - \\
\hline
\end{tabular}




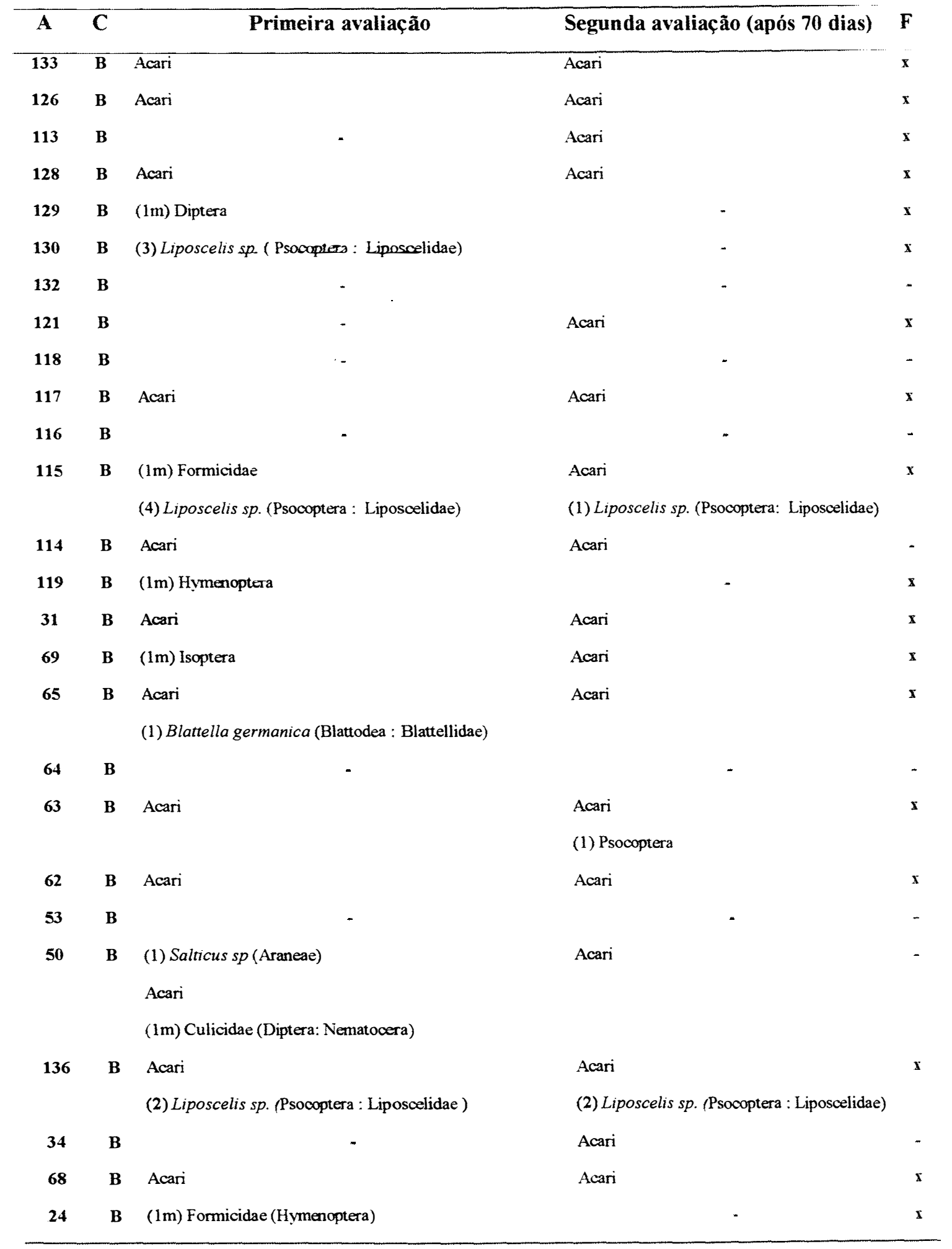




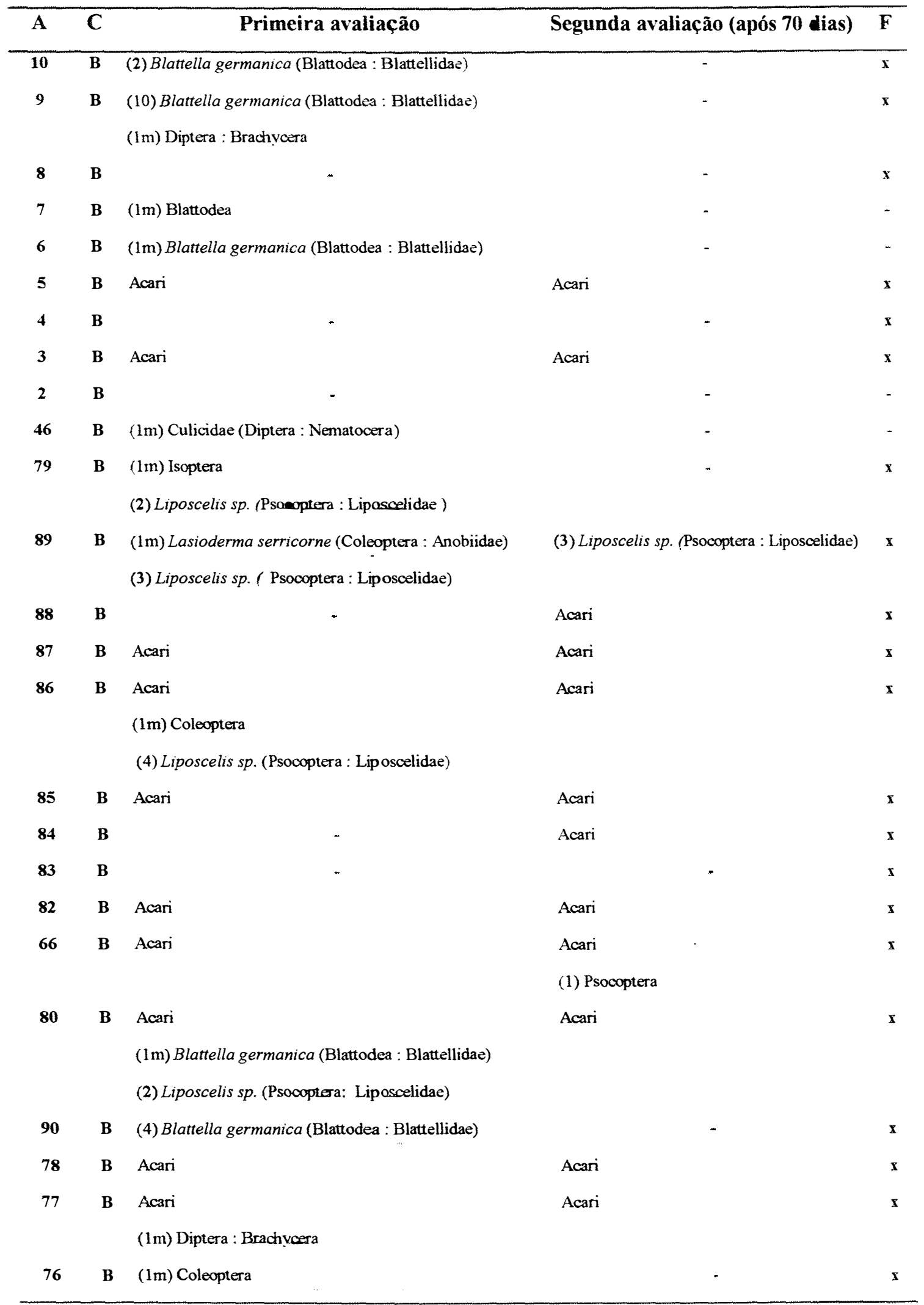




\begin{tabular}{|c|c|c|c|c|}
\hline $\mathbf{A}$ & C & Primeira avaliação & Segunda avaliação (após 70 dias) & $\mathbf{F}$ \\
\hline 75 & $\mathbf{B}$ & $\begin{array}{l}\text { Acari } \\
\text { (14) Liposcelis sp. (Psocoptera : Liposcelidae) }\end{array}$ & $\begin{array}{l}\text { Acari } \\
\text { (2) Liposcelis sp. (Psocoptera: Liposcelidae) }\end{array}$ & $\mathbf{x}$ \\
\hline 74 & B & Acari & Acari & $x$ \\
\hline 73 & B & - & - & $\mathbf{x}$ \\
\hline 72 & B & (1m) Coleoptera & $\begin{array}{l}\text { Acari } \\
\text { (2) Liposcelis sp. (Psocoptera: Liposcelidae) }\end{array}$ & $x$ \\
\hline 71 & B & Acari & $\begin{array}{l}\text { Acari } \\
\text { (1) Gnathocerus cornutus (Coleoptera: } \\
\text { Tenebrionidae) } \\
\text { (1)Liposcelis sp. (Psocoptera: Liposcelidae) }\end{array}$ & $\mathbf{x}$ \\
\hline 70 & B & - & $=$ & - \\
\hline 1 & B & $\begin{array}{l}\text { Acari } \\
(\operatorname{lm}) \text { Araneae }\end{array}$ & Acari & $x$ \\
\hline 81 & B & Acari & Acari & $\mathbf{x}$ \\
\hline 227 & B & - & - & - \\
\hline 235 & B & - & - & $\mathbf{x}$ \\
\hline 222 & B & (3)Liposcelis sp. (Psocoptera : Liposcelidae) & (5)Liposcelis sp. (Psocoptera : Liposcelidae) & $\mathbf{x}$ \\
\hline 223 & B & - & - & $\mathbf{x}$ \\
\hline 224 & B & - & - & $x$ \\
\hline 220 & B & - & - & $\mathbf{x}$ \\
\hline 226 & B & - & - & $\mathbf{x}$ \\
\hline 219 & B & $\begin{array}{l}(1+3 \mathrm{~m}) \text { Liposcelis sp. (Psocoptera : Liposcelidae) } \\
(1 \mathrm{~m}) \text { Psocoptera }\end{array}$ & - & $\mathbf{x}$ \\
\hline 228 & B & - & - & $\mathbf{x}$ \\
\hline 229 & B & - & - & - \\
\hline 230 & B & - & - & $x$ \\
\hline 231 & B & Acari & Acari & $x$ \\
\hline 232 & B & - & - & $\mathbf{x}$ \\
\hline 233 & B & - & - & - \\
\hline 203 & B & - & - & $x$ \\
\hline 225 & B & - & - & $x$ \\
\hline 211 & $\mathbf{B}$ & - & - & $\mathrm{x}$ \\
\hline 134 & B & Acari & Acari & 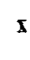 \\
\hline 205 & B & - & Acari & $\mathbf{x}$ \\
\hline
\end{tabular}




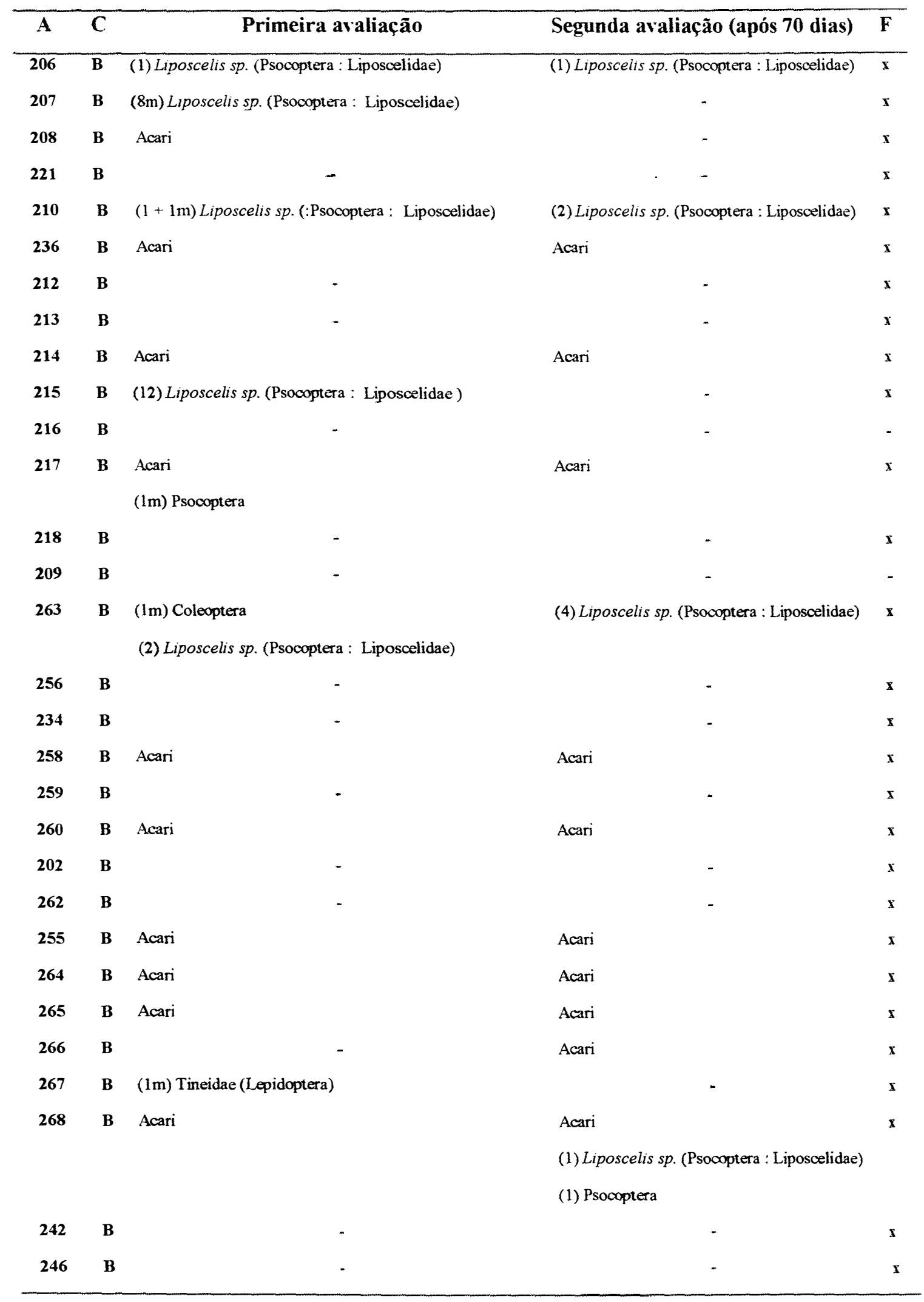




\begin{tabular}{|c|c|c|c|c|}
\hline $\mathbf{A}$ & C & Primeira avaliação & Segunda avaliação (após 70 dias) & $\mathbf{F}$ \\
\hline 269 & B & (lm) Tribolinm sp. (Coleoptera : Tenebrionidae) & $\begin{array}{l}\text { Acari } \\
\text { (3) Liposcelis sp. (Psocoptera : Liposcelidae) }\end{array}$ & $\mathrm{x}$ \\
\hline 270 & $\mathbf{B}$ & $\begin{array}{l}\text { Acari } \\
\text { (2m) Tribolium sp. (Coleoptera : Tenebrionidae) } \\
\text { (1m) Apis mellifera (Hymenoptera : Apidae) } \\
\text { (1m) Cicadellidae ( Hemiptera : Homoptera) }\end{array}$ & $\begin{array}{l}\text { Acari } \\
\text { (1) Liposcelis sp. (Psocoptera : Liposcelidae) }\end{array}$ & $\mathbf{x}$ \\
\hline 261 & B & $\begin{array}{l}\text { Acari } \\
\text { (lm) Cercopidae (Hemiptera : Homoptera) }\end{array}$ & Acari & $\mathbf{x}$ \\
\hline 237 & $\mathbf{B}$ & - & - & $\mathbf{x}$ \\
\hline 238 & B & - & - & - \\
\hline 239 & $\mathbf{B}$ & - & - $\quad-$ & - \\
\hline 240 & $\mathbf{B}$ & - & - & $x$ \\
\hline 241 & $\mathbf{B}$ & Acari & Acari & $\mathbf{x}$ \\
\hline 257 & B & (lm) Formicidae (Hymenoptera) & - & $\mathbf{x}$ \\
\hline 245 & $\mathbf{B}$ & (lm) Forficulidae (Dermaptera) & - & - \\
\hline 254 & $\mathbf{B}$ & $+\quad-$ & Acari & $\mathbf{x}$ \\
\hline 247 & B & (1m) Vespidae (Hymenoptera) & $\cdot$ & $\mathbf{x}$ \\
\hline 248 & $\mathbf{B}$ & Acari & Acari & $\mathbf{x}$ \\
\hline 249 & B & Acari & $\begin{array}{l}\text { Acari } \\
\text { (3) Liposcelis sp. (Psocoptera : Liposcelidae) }\end{array}$ & $\mathbf{x}$ \\
\hline 250 & B & (1m) Coleoptera & (1) Liposcelis sp. (Psocoptera : Liposcelidae) & $\mathbf{x}$ \\
\hline 251 & $\mathbf{B}$ & - & Acari & $\mathbf{x}$ \\
\hline 252 & $\mathbf{B}$ & (lm) Blattella germanica (Blattodea: Blattellidae) & - & $\mathrm{x}$ \\
\hline 253 & B & $\begin{array}{l}\text { Acari } \\
\text { (lm) Braconidae (Hymenoptera) } \\
\text { (1) Psocoptera }\end{array}$ & Acari & $\mathbf{x}$ \\
\hline 160 & $\mathbf{B}$ & Acari & Acari & $\mathbf{x}$ \\
\hline 153 & B & - & - & x \\
\hline 135 & B & $\begin{array}{l}\text { Acari } \\
\text { (4) Liposcelis sp. (Psocoptera : Liposcelidae) }\end{array}$ & $\begin{array}{l}\text { Acari } \\
\text { (3) Liposcelis sp. (Psocoptera: Liposcelidae) }\end{array}$ & $\mathbf{x}$ \\
\hline 155 & B & - & - & $x$ \\
\hline 156 & B & - & - & - \\
\hline 168 & B & (11) Liposcelis sp. (Psocoptera : Liposcelidae) & (2) Liposcelis sp. (Psocoptera: Liposcelidae) & $x$ \\
\hline 157 & $\mathbf{B}$ & - & - & $\mathbf{x}$ \\
\hline
\end{tabular}




\begin{tabular}{|c|c|c|c|c|}
\hline $\mathbf{A}$ & $\mathbf{C}$ & Primeira avaliação & Segunda avaliação (após 70 dias) & $\mathbf{F}$ \\
\hline 159 & B & 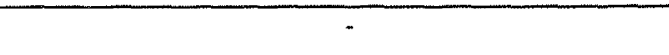 & 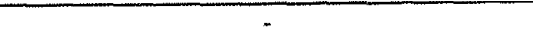 & $\mathbf{x}$ \\
\hline 152 & $\mathbf{B}$ & - & - & $\mathbf{x}$ \\
\hline 161 & $\mathbf{B}$ & $\begin{array}{l}\text { Acari } \\
\text { (1) Psocoptera }\end{array}$ & Acari & $\mathbf{x}$ \\
\hline 162 & B & (lm) Araneae & - & $\mathrm{x}$ \\
\hline 163 & $\mathbf{B}$ & - & - & - \\
\hline 164 & $\mathbf{B}$ & $\begin{array}{l}\text { (1m) Oryzaephilus surinamensis (Coleoptera : } \\
\text { Silvanidae) } \\
\text { (1) Liposcelis sp. (Psocoptera : Liposcelidae) }\end{array}$ & - & $\mathbf{x}$ \\
\hline 165 & $\mathbf{B}$ & - & - & $\mathrm{x}$ \\
\hline 204 & $\mathbf{B}$ & Acari & Acari & $\mathbf{x}$ \\
\hline 167 & $\mathbf{B}$ & $\begin{array}{l}\text { Acari } \\
\text { (lm) Formicidae (Hymenoptera) }\end{array}$ & Acari & $\mathbf{x}$ \\
\hline 158 & $\mathbf{B}$ & - & - & $\mathrm{x}$ \\
\hline 143 & $\mathbf{B}$ & (lm) Hymenoptera & (2) Liposcelis sp. (Psocoptera : Liposcelidae) & $\mathbf{x}$ \\
\hline 271 & $\mathbf{B}$ & (1m) Lasioderma serricorne (Coleoptera : Anobiidae) & - & $\mathbf{x}$ \\
\hline 137 & $\mathbf{B}$ & - & (2) Liposcelis sp. (Psocoptera: Liposcelidae) & $\mathbf{x}$ \\
\hline 138 & B & Acari & Acari & $\mathbf{x}$ \\
\hline 139 & $\mathbf{B}$ & Acari & Acari & $x$ \\
\hline 140 & $\mathbf{B}$ & (1m) Apis mellifera (Hymenoptera : Apidae) & - & $\mathbf{x}$ \\
\hline 154 & $\mathbf{B}$ & Acari & Acari & $\mathbf{x}$ \\
\hline 142 & $\mathbf{B}$ & - & - & $x$ \\
\hline 151 & $\mathbf{B}$ & - & - & $\mathbf{x}$ \\
\hline 144 & $\mathbf{B}$ & - & - & $\mathbf{x}$ \\
\hline 145 & $\mathbf{B}$ & $\begin{array}{l}\text { (1m) Coleoptera } \\
\text { (1m) Diptera : Brachycera }\end{array}$ & - & $\mathbf{x}$ \\
\hline 146 & $\mathbf{B}$ & (lm) Pholcidae (Araneae) & $\begin{array}{l}\text { (2) Liposcelis sp. (Psocoptera: } \\
\text { Liposcelidae) }\end{array}$ & $\mathbf{x}$ \\
\hline 147 & $\mathbf{B}$ & . & - & $\mathbf{x}$ \\
\hline 148 & $\mathbf{B}$ & $\begin{array}{l}\text { (1m) Periplaneta americana (Blattodea : Blattidae) } \\
\text { (1) Liposcelis sp. (Psocoptera : Liposœlidae) }\end{array}$ & $\begin{array}{l}\text { (1) Liposcelis sp. (Psocoptera: } \\
\text { Liposcelidae) }\end{array}$ & $\mathrm{x}$ \\
\hline 149 & $\mathbf{B}$ & $\begin{array}{l}\text { Acari } \\
\text { (1m) Scarabaeidae (Coleoptera) }\end{array}$ & Acari & $\mathbf{x}$ \\
\hline 194 & $\mathbf{B}$ & (1m) Coleoptera & - & $\mathrm{x}$ \\
\hline
\end{tabular}




\begin{tabular}{|c|c|c|c|c|}
\hline $\mathbf{A}$ & $\mathbf{C}$ & Primeira avaliação & Segunda avaliação (após 70 dias) & F \\
\hline 150 & B & $\begin{array}{l}\text { (lm) Pholcidae (Araneae) } \\
\text { (lm) Lepidoptera }\end{array}$ & - & - \\
\hline 141 & B & Acari & Acari & $x$ \\
\hline 187 & B & $\begin{array}{l}\text { Acari } \\
\text { (2m) Sitophilus sp.(Coleoptera : Curculionidae) }\end{array}$ & $\begin{array}{l}\text { Acari } \\
\text { (3) Sitophilus sp. (Coleoptera : } \\
\text { Curculionidae) }\end{array}$ & $x$ \\
\hline 166 & $\mathbf{B}$ & - & - & - \\
\hline 189 & B & Acari & Acari & $\mathbf{x}$ \\
\hline 190 & $\mathbf{B}$ & - & - & $\mathbf{x}$ \\
\hline 191 & B & (4) Liposcelis sp. ( Psocoptera : Liposcelidae) & $\begin{array}{l}\text { (1) Liposcelis sp. (Psocoptera : } \\
\text { Liposcelidae) }\end{array}$ & $x$ \\
\hline 169 & $\mathbf{B}$ & $\begin{array}{l}\text { Acari } \\
(1 \mathrm{~m}) \text { Diptera } \\
\text { (1m) Formicidae (Hymenoptera) }\end{array}$ & $\begin{array}{l}\text { Acari } \\
\text { (3) Liposcelis sp. (Psocoptera : } \\
\text { Liposcelidae) }\end{array}$ & $\mathbf{x}$ \\
\hline 193 & $\mathbf{B}$ & - & - & $\mathbf{x}$ \\
\hline 186 & B & $\begin{array}{l}\text { Acari } \\
\text { (1) Liposcelis sp. ( Psocoptera : Liposcelidae) }\end{array}$ & Acari & $\mathbf{x}$ \\
\hline 195 & $\mathbf{B}$ & - & - & $\mathbf{x}$ \\
\hline 196 & B & - & - & $\mathbf{x}$ \\
\hline 197 & B & - & - & - \\
\hline 198 & $\mathbf{B}$ & (1) Psocoptera & - & $\mathbf{x}$ \\
\hline 199 & $\mathbf{B}$ & - & - & $\mathbf{x}$ \\
\hline 200 & $\mathbf{B}$ & - & - & $\mathbf{x}$ \\
\hline 201 & B & (1m) Blattella germanica ( Blattodea : Blattellidae) & - & $x$ \\
\hline 192 & B & - & - & $\mathbf{x}$ \\
\hline 177 & B & $\begin{array}{l}\text { Acari } \\
\text { (1m) Cryptotermes sp. (Isoptera : Kalotermitidae) }\end{array}$ & $\begin{array}{l}\text { Acari } \\
\text { (6) Liposcelis sp. (Psocoptera: } \\
\text { Liposcelidae) }\end{array}$ & $x$ \\
\hline 170 & $\mathbf{B}$ & - & Acari & $x$ \\
\hline 171 & $\mathbf{B}$ & (1) Liposcelis sp. (Psocoptera : Liposcelidae) & - & - \\
\hline 172 & $\mathbf{B}$ & - & - & $\mathbf{s}$ \\
\hline 173 & $\mathbf{B}$ & Acari & Acari & $\mathbf{x}$ \\
\hline
\end{tabular}




\begin{tabular}{|c|c|c|c|c|}
\hline $\mathbf{A}$ & $\mathbf{C}$ & Primeira avaliação & Segunda avaliação (após 70 dias) & $\bar{F}$ \\
\hline$\overline{185}$ & B & - & - & - \\
\hline \multirow[t]{2}{*}{188} & B & Acari & Acari & $x$ \\
\hline & & & (2) Liposcelis sp. (Psocoptera : Liposcelidae) & \\
\hline \multirow[t]{2}{*}{174} & B & (1m) Vespidae (Hymenoptera) & (1) Liposcelis sp. (Psocoptera : Liposcelidae) & $\mathbf{x}$ \\
\hline & & (2) Psocoptera & & \\
\hline \multirow[t]{2}{*}{176} & $\mathbf{B}$ & Acari & Acari & $\mathbf{x}$ \\
\hline & & (Im) Hymenoptera & & \\
\hline \multirow[t]{2}{*}{178} & $\mathbf{B}$ & Acari & Acari & $\mathrm{x}$ \\
\hline & & (1m) Chrysomelidae (Coleoptera) & & \\
\hline 179 & B & - & - & $\mathrm{x}$ \\
\hline 180 & B & - & $\cdot$ & $\mathbf{x}$ \\
\hline 181 & B & (1m) Lasioderma serricorne (Coleoptera : Anobiidae) & - & $\mathrm{x}$ \\
\hline 182 & $\mathbf{B}$ & (1m) Tribolium castaneum (Coleoptera : Tenebrionidae) & $\cdot$ & - \\
\hline 183 & B & - & - & $\mathbf{x}$ \\
\hline 184 & $\mathbf{B}$ & - & - & $\mathbf{x}$ \\
\hline 175 & B & (1m) Apis mellifera (Hymenoptera : Apidae) & - & - \\
\hline
\end{tabular}


Tabela 2. Total de Indivíduos $(\mathrm{N})$ coletados em amostras provenientes de carrocerias de caminhões realizadas na região metropolitana de São Paulo, entre outubro de 1996 e outubro de 1997. Porcentagem de indivíduos frente ao total $(\% \mathrm{~N})$, porcentagem de indivíduos vivos $(\% \mathrm{NV}) ; \quad$ porcentagem das amostras contendo indivíduos (\%AN), suas freqüências (F) e constâncias (C).

\begin{tabular}{|c|c|c|c|c|c|c|}
\hline & N & $\% N$ & $F$ & $\%$ NV & \%AN & c \\
\hline Insecta & 299 & & & 63,16 & 41,70 & $y$ \\
\hline Blattodea & 25 & 8,36 & pf & 64,00 & 4,42 & 2 \\
\hline Blattellidae & 23 & 7,69 & & 69,56 & & \\
\hline Blattella germanica & 23 & 7,69 & & 69,56 & & \\
\hline Blattidae & 1 & 0,33 & & & & \\
\hline Periplaneta americana & 1 & 0,33 & & & & \\
\hline não identificado & 1 & 0,33 & & & & \\
\hline Coleoptera & 30 & 10,03 & pf & 13,33 & $\mathbf{8 , 4 9}$ & $z$ \\
\hline Anobiidae & 3 & 1,00 & & & & \\
\hline Lasioderma sersicome & 3 & 1,00 & & & & \\
\hline Chrysomelidae & 1 & 0,33 & & & & \\
\hline Coccinellidae & 1 & 0,33 & & & & \\
\hline Coleomegila maculata & 1 & 0,33 & & & & \\
\hline Curculionidae & 5 & 1,67 & & 60,00 & & \\
\hline Sitophilus sp. & 5 & 1,67 & & 60,00 & & \\
\hline Scarabaeidae & 1 & 0,33 & & & & \\
\hline Silvanidae & 1 & 0,33 & & & & \\
\hline Oryzaephilus surinamensis & 1 & 0.33 & & & & \\
\hline Tenebrionidae & 8 & 2,68 & & 12,50 & & \\
\hline Gnathocerus sp. & 1 & 0,33 & & 100,00 & & \\
\hline Tribolium sp. & 3 & 1,00 & & & & \\
\hline Tribolium castaneum & 4 & 1,33 & & & & \\
\hline nāo identificado & 10 & 3,34 & & & & \\
\hline Dermaptera & 1 & 0,33 & pf & & 0,37 & $z$ \\
\hline Forficulidae & 1 & 0.33 & & & & \\
\hline Diptera & 11 & 3,69 & pf & & 4,06 & $z$ \\
\hline Nematocera & 2 & 0,67 & & & & \\
\hline Culicidae & 2 & 0,67 & & & & \\
\hline Brachycera & 7 & 2,34 & & & & \\
\hline Muscidae & 9 & $\Omega 33$ & & & & \\
\hline nāo identificado & 8 & 2,68 & & & & \\
\hline Hemiptera-Homoptera & 3 & 1,00 & pf & & 1,11 & $\mathbf{z}$ \\
\hline Cercopidae & 1 & 0,33 & & & & \\
\hline Cicadellidae & 2 & $\Omega 67$ & & & & \\
\hline
\end{tabular}

$\mathrm{f}=$ freqüente $\mathrm{pf}=$ pouco freqüente

$\mathrm{x}=$ constante $\mathrm{y}=$ acessório $\mathrm{z}=$ acidental 
Tabela 2. Continuação

\begin{tabular}{|c|c|c|c|c|c|c|}
\hline & $\mathrm{N}$ & $\% N$ & $F$ & $\% N V$ & $\%$ AN & C \\
\hline Hymenoptera & 45 & 15,05 & pf & & 10,33 & $z$ \\
\hline Apidae & 6 & 200 & & & & \\
\hline Apis mellifera & 6 & 2,00 & & & & \\
\hline Braconidae & 1 & 0,33 & & & & \\
\hline Formicidae & 31 & 10,37 & & & & \\
\hline Vespidae & 2 & 0,67 & & & & \\
\hline não identificado & 5 & 1,67 & & & & \\
\hline Isoptera & 4 & 1,33 & pf & & 1,48 & $z$ \\
\hline Kalotermitidae & 1 & 0,33 & & & & \\
\hline Cryptotermes sp. & 1 & 0.33 & & & & \\
\hline não identificado & 3 & 1,00 & & & & \\
\hline Lepidoptera & 3 & 1,00 & pf & & 1,11 & $\mathbf{z}$ \\
\hline Tineidae & 1 & 0,33 & & & & \\
\hline não identificado & 2 & 0.67 & & & & \\
\hline Psocoptera & 177 & 59,20 & $f$ & 92,09 & 17,34 & $\mathbf{z}$ \\
\hline Liposcelidae & 167 & 55,85 & & 92,81 & & \\
\hline Liposcelis sp. & 167 & 55,85 & & 92,81 & & \\
\hline não identificado & .9 & 3,01 & & & & \\
\hline Arachinida & 6 & & & & 44,28 & $y$ \\
\hline Araneae & 6 & & & 16,67 & 2,22 & $z$ \\
\hline Pholcidae & 2 & & & & & \\
\hline Saltidae & 1 & & & 100 & & \\
\hline Salticus sp. & 1 & & & 100,00 & & \\
\hline não identificado & 3 & & & & & \\
\hline Acari & & & & & 43,17 & y \\
\hline Fragmentos de insetos & & & & & 81,18 & $x$ \\
\hline
\end{tabular}

$f=$ freqüente $p f=$ pouco freqüente

$\mathrm{x}=$ constante $\mathrm{y}=$ acessório $\mathrm{z}=$ acidental 
Tabela 3. Indivíduos $(\mathrm{N})$ coletados em amostras provenientes de carrocerias de caminhões realizadas na região metropolitana de São Paulo, de outubro de 1996 a outubro de 1997. Porcentagem de indivíduos frente ao total $(\% \mathrm{~N})$, porcentagem de indivíduos vivos $(\% \mathrm{NV})$; porcentagem das amostras contendo indivíduos (\%AN), suas freqüências $\quad$ (F) e constâncias $(C)$. Primeira avaliação

\begin{tabular}{|c|c|c|c|c|c|c|}
\hline & $\mathrm{N}$ & $\% N$ & $\mathrm{~F}$ & $\% N V$ & $\% A N$ & C \\
\hline Insecta & 231 & & & 49,78 & 34,32 & $\mathbf{y}$ \\
\hline Blattodea & 25 & 10,82 & pf & 64,00 & 4,43 & $z$ \\
\hline Blattellidae & 23 & 9,96 & & 69,56 & & \\
\hline Blattella germanica & 23 & 9,96 & & 69,56 & & \\
\hline Blattidae & 1 & 0,43 & & & & \\
\hline Periplaneta americana & 1 & 0,43 & & & & \\
\hline não identificado & 1 & 0,43 & & & & \\
\hline Coleoptera & 26 & 11,25 & $\mathbf{f}$ & & 7,75 & $\mathbf{z}$ \\
\hline Anobiidae & 3 & 1,3 & & & & \\
\hline Lasioderma serricorne & 3 & 1,30 & & & & \\
\hline Chrysomelidae & 1 & 0,43 & & & & \\
\hline Coccinellidae & 1 & 0,43 & & & & \\
\hline Coleomegilla maculata & 1 & 0,43 & & & & \\
\hline Curculionidae & 2 & 0,87 & & & & \\
\hline Sitophilus sp. & 2 & 0,87 & & & & \\
\hline Scarabaeidae & 1 & 0,43 & & & & \\
\hline Silvanidae & 1 & 0,43 & & & & \\
\hline Oryzaephilus surinamensis & 1 & 0,43 & & & & \\
\hline Tenebrionidae & 7 & 3,03 & & & & \\
\hline Tribolium sp. & 3 & 1,30 & & & & \\
\hline Tribolium castaneum & 4 & 1,73 & & & & \\
\hline não identificado & 10 & 4,33 & & & & \\
\hline Dermaptera & 1 & 0,43 & pf & & 0,37 & $\mathbf{z}$ \\
\hline Forficulidae & 1 & 0,43 & & & & \\
\hline Diptera & 11 & 4,76 & pf & & 4,06 & z \\
\hline Nematocera & 2 & 0,87 & & & & \\
\hline Culicidae & 2 & 0,87 & & & & \\
\hline Brachycera & 7 & 3,03 & & & & \\
\hline Muscidae & 1 & 0,43 & & & & \\
\hline nāo identificado & 6 & 2,60 & & & & \\
\hline Hemiptera-Homoptera & 3 & 1,30 & pf & & 1,11 & $z$ \\
\hline Cercopidae & 1 & 0,43 & & & & \\
\hline Cicadellidae & 2 & 0,87 & & & & \\
\hline
\end{tabular}

continuação

$f=$ freqüente $p f=$ pouco freqüente

$\mathrm{x}=$ constante $\mathrm{y}=$ acessório $\mathrm{z}=$ acidental 
Tabela 3. Continuação

\begin{tabular}{|c|c|c|c|c|c|c|}
\hline & $N$ & $\% \mathrm{~N}$ & $F$ & $\% \mathrm{NV}$ & $\%$ AN & C \\
\hline Hymenoptera & 45 & 19,48 & $\mathrm{pf}$ & & 10,33 & 2 \\
\hline Apidae & 6 & 260 & & & & \\
\hline Apis mellifera & 6 & 2,60 & & & & \\
\hline Braconidae & 1 & 0,43 & & & & \\
\hline Formicidae & 31 & 13,42 & & & & \\
\hline Vespidae & 2 & 0,87 & & & & \\
\hline não identificado & 5 & 2,16 & & & & \\
\hline Isoptera & 4 & 1,73 & pf & & 1,48 & $z$ \\
\hline Kalotermitidae & 1 & 0,43 & & & & \\
\hline Cryptotermes sp. & 1 & 0.43 & & & & \\
\hline nāo identificado & 3 & 1,30 & & & & \\
\hline Lepidoptera & 3 & 1,30 & pf & & 1,11 & $z$ \\
\hline Tineidae & 1 & 0,43 & & & & \\
\hline não identificado & 2 & 0,86 & & & & \\
\hline Psocoptera & 113 & 48,91 & $f$ & 87,93 & 11,07 & $z$ \\
\hline Liposcelidae & 106 & 45,89 & & 88,68 & & \\
\hline Liposcelis sp. & 106 & 45,89 & & 88,68 & & \\
\hline não identificado & .7 & 3,03 & & & & \\
\hline Arachinida & & & & & 36,53 & $y$ \\
\hline Araneae & 6 & & & 16,67 & 2,22 & $z$ \\
\hline Pholcidae & 2 & & & & & \\
\hline Saltidae & 1 & & & & & \\
\hline Selticus sp. & 1 & & & 100,00 & & \\
\hline não identificado & 3 & & & & & \\
\hline Acari & & & & & 35,42 & $y$ \\
\hline
\end{tabular}

$f=$ freqüente $p f=$ pouco freqüente

$x=$ constante $y=$ acessónio $z=$ acidental 
Tabela 4. Indivíduos (N) coletados em amostras provenientes de carrocerias de caminhões realizadas na região metropolitana de São Paulo, de outubro de 1996 a outubro de 1997. Porcentagem de indivíduos frente ao total $(\% \mathrm{~N})$, porcentagem de indivíduos vivos (\%NV); porcentagem das amostras contendo indivíduos (\%AN), suas freqüências $(\mathrm{F})$ e constâncias (C). Análise após setenta dias de quarentena

\begin{tabular}{|c|c|c|c|c|c|c|}
\hline & $\mathbf{N}$ & $\% N$ & $F$ & $\%$ NV & $\%$ AN & C \\
\hline Insecta & 68 & & & & 12,17 & $z$ \\
\hline Coleoptera & 4 & 5,88 & pf & 100,00 & 0,73 & $z$ \\
\hline Curculionidae & 3 & 4,41 & & 100,00 & & \\
\hline Sitophilus sp. & 3 & 4,41 & & 100,00 & & \\
\hline Tenebrionidae & 1 & 1,47 & & 100,00 & & \\
\hline Gnathocerus.sp. & 1 & 1.47 & . & 100,000 & & \\
\hline Psocoptera & 64 & 94,12 & $f$ & 100.00 & 12,18 & 2 \\
\hline Liposcelidae & 62 & 91,18 & & 100,00 & & \\
\hline Liposcelis sp. & 62 & 91,18 & & 100,00 & & \\
\hline não identificado & -2 & 2,94 & & & & \\
\hline Arachinida & & & & & 42,80 & y \\
\hline Acari & & & & & 42,80 & y \\
\hline
\end{tabular}

$f=$ freqüente $p f=$ pouco freqüente

$\mathrm{x}=$ constante $\mathrm{y}=$ acessório $\mathrm{z}=$ acidental 
Tabela 5. Indivíduos $(\mathrm{N})$ coletados em amostras provenientes de carrocerias de caminhões baús, realizadas na região metropolitana de São Paulo, de outubro de 1996 a outubro de 1997. Porcentagem de indivíduos frente ao total $(\% \mathrm{~N})$, porcentagem de indivíduos vivos (\%NV); porcentagem das amostras contendo indivíduos (\%AN), suas freqüências $(F)$ e constâncias $(C)$.

\begin{tabular}{|c|c|c|c|c|c|c|}
\hline & $\mathbf{N}$ & $\% \mathrm{~N}$ & $F$ & $\%$ NV & $\%$ AN & C \\
\hline Insecta & 279 & & & 64,87 & 45,09 & $y$ \\
\hline Blattodea & 25 & 8,96 & pf & 64,00 & 5,36 & $z$ \\
\hline Blattellidae & 23 & 8,24 & & 69,56 & & \\
\hline Blattella germanica & 23 & 8,24 & & 69,56 & & \\
\hline Blattidae & 1 & 0,36 & & & & \\
\hline Periplaneta americana & 1 & 0,36 & & & & \\
\hline nāo identificado & 2 & $\Omega>2$ & & & & \\
\hline Coleoptera & 24 & 8,60 & pf & 16,67 & 8,48 & $z$ \\
\hline Anobiidae & 3 & 1,07 & & & & \\
\hline Lasioderma serricome & 3 & 1,07 & & & & \\
\hline Chrysomelidae & 1 & 0,36 & & & & \\
\hline Curculionidae & 5 & 1,79 & & & & \\
\hline Sitophilus sp. & 5 & 1,79 & & 60,00 & & \\
\hline Scarabaeidae & 1 & 0,36 & & & & \\
\hline Silvanidae & 1 & 0,36 & & & & \\
\hline Oryzaephilus surinamensis & 1 & 0,36 & & & & \\
\hline Tenebrionidae & 5 & 1,79 & & & & \\
\hline Gnathocerus sp. & 1 & 0,36 & & 100,00 & & \\
\hline Triboliumsp. & 3 & 1,07 & & & & \\
\hline Tribolium castaneum & 1 & 0,36 & & & & \\
\hline não identificado & 8 & 2,87 & & & & \\
\hline Dermaptera & 1 & 0,36 & pf & & 0,45 & $\mathbf{z}$ \\
\hline Forficulidae & 1 & 0,36 & & & & \\
\hline Diptera & 8 & 2,87 & pf & & 3,57 & $\mathbf{z}$ \\
\hline Nematocera & 2 & 0,72 & & & & \\
\hline Culicidae & 2 & 0,36 & & & & \\
\hline Brachycera & 6 & 2.15 & & & & \\
\hline Muscidae & 1 & 0,36 & & & & \\
\hline não identificado & 5 & 1,79 & & & & \\
\hline Hemiptera-Homoptera & 2 & 0,72 & pf & & 0,89 & $\mathbf{z}$ \\
\hline Cercopidae & 1 & 0.36 & & & & \\
\hline Cicadellidae & 1 & 0,36 & & & & \\
\hline
\end{tabular}

continuação

$\mathrm{f}=$ freqüente $\mathrm{pf}=$ pouco freqüente

$\mathrm{x}=$ constante $\mathrm{y}=$ acessório $\mathrm{z}=$ acidental 
Tabela 5. Continuação.

\begin{tabular}{|c|c|c|c|c|c|c|}
\hline & $\mathrm{N}$ & $\% \mathrm{~N}$ & $\mathrm{~F}$ & $\%$ NV & $\%$ AN & C \\
\hline Hymenoptera & 40 & 14,34 & $f$ & & 10,71 & 2 \\
\hline Apidae & 4 & 1,43 & & & & \\
\hline Apis mellifera & 4 & 1,43 & & & & \\
\hline Braconidae & 1 & 0,36 & & & & \\
\hline Formicidae & 29 & 10,39 & & & & \\
\hline Vespidae & 2 & 0,72 & & & & \\
\hline não identificado & 4 & 1,43 & & & & \\
\hline Isoptera & 3 & 1,07 & pf & & 1,34 & $\mathbf{z}$ \\
\hline Kalotermitidae & 1 & 0,36 & & & & \\
\hline Cryptotermes sp. & 1 & 0,36 & & & & \\
\hline não identificado & 2 & 0,72 & & & & \\
\hline Lepidoptera & 2 & 0,72 & pf & & 0,89 & $z$ \\
\hline Tineidae & 1 & 0,36 & & & & \\
\hline não identificado & 1 & 0,36 & & & & \\
\hline Psocoptera & 174 & 62,36 & f & 92,53 & 20,54 & $z$ \\
\hline Liposcelidae & 165 & 59,14 & & 93,05 & & \\
\hline Liposcelis sp. & 165 & 59,14 & & 93,05 & & \\
\hline não identificado & 9 & 4.21 & & & & \\
\hline Arachinida & & & & & 44,64 & $y$ \\
\hline Araneae & 6 & & & 16,67 & 2,68 & 2 \\
\hline Pholcidae & 2 & & & & & \\
\hline Saltidae & 1 & & & 100,00 & & \\
\hline Salticus sp. & 1 & & & 100,00 & & \\
\hline Acari & & & & & 43,30 & y \\
\hline Fragmentos de insetos & & & & & 85,72 & $x$ \\
\hline
\end{tabular}

$f=$ freqüente $p f=$ pouco freqüente

$\mathrm{x}=$ constante $\mathrm{y}=$ acessório $\mathrm{z}=$ acidental 
Tabela 6. Indivíduos (N) coletados em amostras provenientes de carrocerias de caminhões baús, realizadas na região metropolitana de São Paulo, de outubro de 1996 a outubro de 1997. Porcentagem de indivíduos frente ao total $(\% \mathrm{~N})$, porcentagem de indivíduos vivos $(\% \mathrm{NV})$; porcentagem das amostras contendo individuos $(\% \mathrm{AN}), \quad$ suas freqüências $(\mathrm{F}) \mathrm{e}$ constâncias (C). Primeira avaliação

\begin{tabular}{|c|c|c|c|c|c|c|}
\hline & $N$ & $\% \mathrm{~N}$ & $F$ & $\%$ NV & $\%$ AN & $C$ \\
\hline Insecta & 214 & & & 53,74 & 36,61 & $\mathbf{y}$ \\
\hline Blattodea & 25 & 11,68 & $\mathbf{f}$ & 64,00 & 5,36 & $z$ \\
\hline Blattellidae & 23 & 10,75 & & 69,56 & & \\
\hline Blattella germanica & 23 & 10,75 & & 69,56 & & \\
\hline Blattidae & 1 & 0,47 & & & & \\
\hline Periplaneta americana & 1 & 0,47 & & & & \\
\hline não identificado & 2 & 0,93 & & & & \\
\hline Coleoptera & 20 & 9,34 & pf & & 8,03 & $z$ \\
\hline Anobiidae & 3 & 1,40 & & & & \\
\hline Lasioderma serricome & 3 & 1,40 & & & & \\
\hline Chrysomelidae & 1 & 0,47 & & & & \\
\hline Curculionidae & 2 & 0,93 & & & & \\
\hline Sitophilus sp. & 2 & 0,93 & & & & \\
\hline Scarabaeidae & 1 & 0,47 & & & & \\
\hline Silvanidae & 1 & 0,47 & & & & \\
\hline Oryzaephilus surinamensis & 1 & 0,47 & & & & \\
\hline Tenebrionidae & 4 & 1,87 & & & & \\
\hline Tribolium sp. & 3 & 1,40 & & & & \\
\hline Tribolium castaneum & 1 & 0,47 & & & & \\
\hline não identificado & 8 & 3,74 & & & & \\
\hline Dermaptera & 1 & 0,47 & pf & & 0,45 & $z$ \\
\hline Forficulidae & 1 & 0,47 & & & & \\
\hline Diptera & 8 & 3,74 & pf & & 3,57 & $\mathbf{z}$ \\
\hline Nematocera & 2 & 0,93 & & & & \\
\hline Culicidae & 2 & 0,93 & & & & \\
\hline Brachycera & 6 & 2,80 & & & & \\
\hline Muscidae & 1 & 0,47 & & & & \\
\hline não identificado & 5 & 2,34 & & & & \\
\hline Hemiptera-Homoptera & 2 & 0,93 & pf & & 0,89 & $z$ \\
\hline Cercopidae & 1 & 0,47 & & & & \\
\hline Cicadellidae & 1 & 0,47 & & & & \\
\hline
\end{tabular}

continuação

$f=$ freqüente $p f=$ pouco freqüente

$\mathrm{x}=$ constante $\mathrm{y}=$ acessório $\mathrm{z}=$ acidental 
Tabela 6. Continuação.

\begin{tabular}{|c|c|c|c|c|c|c|}
\hline & $\mathbf{N}$ & $\% N$ & $F$ & $\% N V$ & $\%$ AN & C \\
\hline Hymenoptera & 40 & 18,69 & $\bar{f}$ & & 10,71 & $z$ \\
\hline Apidae & 4 & 1,87 & & & & \\
\hline Apis mellifera & 4 & 1,87 & & & & \\
\hline Braconidae & 1 & 0,47 & & & & \\
\hline Formicidae & 29 & 13,55 & & & & \\
\hline Vespidae & 2 & 0,93 & & & & \\
\hline não identificado & 4 & 1,87 & & & & \\
\hline Isoptera & 3 & 1,40 & pf & & 1,34 & $\mathbf{z}$ \\
\hline Kalotermitidae & 1 & 0,47 & & & & \\
\hline Cryptotermes sp. & 1 & 0,47 & & & & \\
\hline não identificado & 2 & 0,93 & & & & \\
\hline Lepidoptera & 2 & 0,93 & pf & & 0,89 & $z$ \\
\hline Tineidae & 1 & 0,47 & & & & \\
\hline não identificado & 1 & 0,47 & & & & \\
\hline Psocoptera & 113 & 52,80 & f & 87,61 & 13,39 & $\mathbf{z}$ \\
\hline Liposcelidae & 106 & 49,53 & & 88,68 & & \\
\hline Liposcelis sp. & 106 & 49,53 & & 88,68 & & \\
\hline não identificado & 7 & 3,27 & & & & \\
\hline Arachinida & & & & & 36,39 & $y$ \\
\hline Araneae & 6 & & & 16,67 & 2,23 & $\mathbf{z}$ \\
\hline Pholcidae & 2 & & & & & \\
\hline Saltidae & 1 & & & 100,00 & & \\
\hline Salticus sp. & 1 & & & 100,00 & & \\
\hline Acari & & & & & 35,27 & $y$ \\
\hline
\end{tabular}

$\mathrm{f}=$ freqüente $\mathrm{pf}=$ pouco freqüente

$\mathrm{x}=$ constante $\mathrm{y}=$ acessório $\mathrm{z}=$ acidental 
Tabela 7. Indivíduos (N) coletados em amostras provenientes de carrocerias de caminhões baús, realizadas na região metropolitana de São Paulo, de outubro de 1996 a outubro de 1997. Porcentagem de indivíduos frente ao total $(\% \mathrm{~N})$, porcentagem de indivíduos vivos $(\% \mathrm{NV})$; porcentagem amostras contendo indivíduos $(\% \mathrm{AN})$, suas freqüências (F) e constâncias (C). Análise após $\mathbf{7 0}$ dias de quarentena.

\begin{tabular}{|c|c|c|c|c|c|c|}
\hline & $N$ & $\% N$ & $F$ & $\% N V$ & $\% A N$ & C \\
\hline Insecta & 66 & & & 100,00 & 14,29 & $z$ \\
\hline Coleoptera & 4 & 6,06 & pf & 100,00 & 0,89 & $\mathbf{z}$ \\
\hline Curculionidae & 3 & 4,64 & & 100,00 & & \\
\hline Sitophilus sp. & 3 & 4,64 & & 100,00 & & \\
\hline Tenebrionidae & 1 & 1,51 & & 100,00 & & \\
\hline Gnathocerus sp. & 1 & 1,51 & & 100,00 & & \\
\hline Psocoptera & 62 & 93,94 & $f$ & 100.00 & 14,29 & 2 \\
\hline Liposcelidae & 59 & 89,39 & & 100,00 & & \\
\hline Liposcelis sp. & 59 & 89,39 & & 100,00 & & \\
\hline não identificado & 7 & 10,61 & & & & \\
\hline Arachinida & & & & & 42,85 & $y$ \\
\hline Acari & & & & & 42,85 & $y$ \\
\hline
\end{tabular}

$\mathrm{f}=$ freqüente $\mathrm{pf}=$ pouco freqüente

$\mathrm{x}=$ constante $\mathrm{y}=$ acessório $\mathrm{z}=$ acidental 
Tabela 8. Indivíduos $(\mathrm{N})$ coletados em amostras provenientes de carrocerias de caminhões lonados, realizadas na região metropolitana de São Paulo, de outubro de 1996 a outubro de 1997. Porcentagem de indivíduos frente ao total $(\% \mathrm{~N})$, porcentagem de indivíduos vivos $(\% \mathrm{NV})$; porcentagem das amostras contendo indivíduos (\%AN), suas freqüências $(F)$ e constâncias $(C)$.

\begin{tabular}{|c|c|c|c|c|c|c|}
\hline & $\mathrm{N}$ & $\% N$ & $F$ & $\% N V$ & $\%$ AN & $C$ \\
\hline Insecta & 19 & & & 10,53 & 25,53 & $\bar{y}$ \\
\hline Coleoptera & 6 & 31,57 & $f$ & & 8,51 & $z$ \\
\hline Coccinellidae & 1 & 5,26 & & & & \\
\hline Coleomegila maculata & 1 & 5,26 & & & & \\
\hline Tenebrionidae & 3 & 15,79 & & & & \\
\hline Tribolium castaneum & 3 & 15,79 & & & & \\
\hline não identificado & 2 & 10,53 & & & & \\
\hline Diptera & 3 & 15,79 & $f$ & & 6,38 & $z$ \\
\hline Brachycera & 3 & 15,79 & & & & \\
\hline nāo identificado & 3 & 15,79 & & & & \\
\hline Hemiptera-Homoptera & 1 & 5,26 & pf & & 2,13 & $z$ \\
\hline Cicadellidae & 1 & 5,26 & & & & \\
\hline Hymenoptera & 5 & 26,31 & $f$ & & 4,24 & $z$ \\
\hline Apidae & 2 & 10,53 & & & & \\
\hline Apis mellifera & 2 & 10,53 & & & & \\
\hline Formicidae & 2 & 10,53 & & & & \\
\hline nāo identificado & 1 & 5,26 & & & & \\
\hline Isoptera & 1 & 5,26 & pf & & 2,13 & 2 \\
\hline não identificado & 1 & 5.26 & & & & \\
\hline Lepidoptera & 1 & 5,26 & pf & & 2,13 & 2 \\
\hline nāo identificado & 1 & 5.26 & & & & \\
\hline Psocoptera & 2 & 10,53 & pf & 100,00 & 2,13 & 2 \\
\hline Liposcelidae & 2 & 10,53 & & 100,00 & & \\
\hline Liposcelis sp. & 2 & 10,53 & & 100,00 & & \\
\hline Arachinida & & & & & 42,55 & $\mathbf{y}$ \\
\hline Acari & & & & & 42,55 & $y$ \\
\hline Fragmentos de insetos & & & & & 59,57 & $\mathrm{x}$ \\
\hline
\end{tabular}

$f=$ freqüente $p f=$ pouco freqüente

$\mathrm{x}=$ constante $\mathrm{y}=$ acessório $\mathrm{z}=$ acidental 
Tabela 9 : Indivíduos $(\mathbb{N})$ coletados em amostras provenientes de carrocerias de caminhões lonados realizadas na região metropolitana de São Paulo, de outubro de 1996 a outubro de 1997. Porcentagem de indivíduos frente ao total $(\% \mathrm{~N})$, porcentagem de individuos vivos (\%NV); porcentagem das amostras contendo indivíduos $(\% \mathrm{AN}), \quad$ suas. freqüências $(\mathrm{F}) \mathrm{e}$ constâncias (C). Primeira avaliação.

\begin{tabular}{|c|c|c|c|c|c|c|}
\hline & $N$ & $\% \mathrm{~N}$ & $\mathrm{~F}$ & $\%$ NV & $\%$ AN & C \\
\hline Insecta & 17 & & & & 23,40 & $\bar{z}$ \\
\hline Coleoptera & 6 & 35,29 & $f$ & & 8,51 & $z$ \\
\hline Coccinellidae & 1 & 5,88 & & & & \\
\hline Coleomegila maculata & 1 & 5,88 & & & & \\
\hline Tenebrionidae & 3 & 17,65 & & & & \\
\hline Tribolium castaneum & 3 & 17,65 & & & & \\
\hline não identificado & 2 & 11,76 & & & & \\
\hline Diptera & 3 & 17,65 & $\mathbf{f}$ & & 6,38 & $z$ \\
\hline Brachycera & 3 & 17,65 & & & & \\
\hline não identificado & 3 & 17,65 & & & & \\
\hline Hemiptera-Homoptera & 1 & 5,88 & pf & & 2,13 & $\mathbf{z}$ \\
\hline Cicadellidae & 1 & 5,88 & & & & \\
\hline Hymenoptera & 5 & 29,41 & f & & 4,24 & $\mathbf{z}$ \\
\hline Apidae & 2 & 11,76 & & & & \\
\hline Apis mellifera & 2 & 11,76 & & & & \\
\hline Formicidae & 2 & 11,76 & & & & \\
\hline não identificado & 1 & 5,88 & & & & \\
\hline Isoptera & 1 & 5,88 & pf & & 2,13 & $z$ \\
\hline não identificado & 1 & 5,88 & & & & \\
\hline Lepidoptera & 1 & 5,88 & pf & & 2,13 & $z$ \\
\hline não identificado & 1 & 5.88 & & & & \\
\hline Arachinida & & & & & 36,17 & y \\
\hline Acari & & & & & 36,17 & $\mathbf{y}$ \\
\hline
\end{tabular}

$\mathrm{f}=$ freqüente $\mathrm{pf}=$ pouco freqüente

$\mathrm{x}=$ constante $\mathrm{y}=$ acessório $\mathrm{z}=$ acidental 
Tabela 10. Indivíduos (N) coletados em amostras provenientes de carrocerias de caminhões lonados, realizadas na região metropolitana de São Paulo, de outubro de 1996 a outubro de 1997. Porcentagem de indivíduos frente ao total $(\% \mathrm{~N}), \quad$ porcentagem de indivíduos vivos (\%NV); porcentagem das amostras contendo indivíduos (\%AN), suas freqüências $(\mathrm{F}) \quad \mathrm{e}$ constâncias $(\mathrm{C})$. Análises após $\mathbf{7 0}$ dias de quarentena.

\begin{tabular}{|c|c|c|c|c|c|c|}
\hline & $N$ & $\% N$ & $F$ & $\%$ NV & $\%$ AN & C \\
\hline Insecta & 2 & & & 100,00 & 2,13 & $\bar{z}$ \\
\hline Psocoptera & 2 & 100,00 & & 100,00 & 2,13 & $z$ \\
\hline Liposcelidae & 2 & 100,00 & & 100,00 & & \\
\hline Liposcelis sp. & 2 & 100,00 & & 100,00 & & \\
\hline $\begin{array}{l}\text { Arachinida } \\
\text { Acari }\end{array}$ & & & & & $\begin{array}{l}42,55 \\
42,55\end{array}$ & $\begin{array}{l}y \\
y\end{array}$ \\
\hline
\end{tabular}

$f=$ freqüente $p f=$ pouco freqüente

$\mathrm{x}=$ constante $\mathrm{y}=$ acessório $\mathrm{z}=$ acidental 